\title{
Versatile Surface Electrodes for Combined Electrophysiology and Two-Photon Imaging of the Mouse Central Nervous System
}

\author{
Michael Schweigmann ${ }^{1,2 \dagger}$, Laura C. Caudal ${ }^{1 \dagger}$, Gebhard Stopper ${ }^{1}$, Anja Scheller ${ }^{1}$, \\ Klaus P. Koch ${ }^{2}$ and Frank Kirchhoff ${ }^{1 *}$ \\ ${ }^{1}$ Molecular Physiology, Center for Integrative Physiology and Molecular Medicine (CIPMM), University of Saarland, Homburg, \\ Germany, ${ }^{2}$ Department of Electrical Engineering, Trier University of Applied Sciences, Trier, Germany
}

OPEN ACCESS

Edited by:

Francesca Boscia,

University of Naples Federico II, Italy

Reviewed by:

Bernd Kuhn,

Okinawa Institute of Science and Technology Graduate University,

Japan

Yu-Feng Wang,

Harbin Medical University, China

*Correspondence:

Frank Kirchhoff

frank.kirchhoff@uks.eu

${ }^{\dagger}$ These authors have contributed equally to this work

Specialty section:

This article was submitted to

Non-Neuronal Cells,

a section of the journal

Frontiers in Cellular Neuroscience

Received: 04 June 2021

Accepted: 19 July 2021

Published: 10 August 2021

Citation:

Schweigmann M, Caudal LC, Stopper G, Scheller A, Koch KP and Kirchhoff $F$ (2021) Versatile Surface

Electrodes for Combined Electrophysiology and Two-Photon Imaging of the Mouse Central

Nervous System.

Front. Cell. Neurosci. 15:720675. doi: 10.3389/fncel.2021.720675
Understanding and modulating CNS function in physiological as well as pathophysiological contexts remains a significant ambition in research and clinical applications. The investigation of the multifaceted CNS cell types including their interactions and contributions to neural function requires a combination of the state-ofthe-art in vivo electrophysiology and imaging techniques. We developed a novel type of liquid crystal polymer (LCP) surface micro-electrode manufactured in three customized designs with up to 16 channels for recording and stimulation of brain activity. All designs include spare central spaces for simultaneous 2P-imaging. Nanoporous platinumplated contact sites ensure a low impedance and high current transfer. The epidural implantation of the LCP micro-electrodes could be combined with standard cranial window surgery. The epidurally positioned electrodes did not only display long-term biocompatibility, but we also observed an additional stabilization of the underlying CNS tissue. We demonstrate the electrode's versatility in combination with in vivo 2P-imaging by monitoring anesthesia-awake cycles of transgenic mice with GCaMP3 expression in neurons or astrocytes. Cortical stimulation and simultaneous $2 \mathrm{P} \mathrm{Ca}^{2+}$ imaging in neurons or astrocytes highlighted the astrocytes' integrative character in neuronal activity processing. Furthermore, we confirmed that spontaneous astroglial $\mathrm{Ca}^{2+}$ signals are dampened under anesthesia, while evoked signals in neurons and astrocytes showed stronger dependency on stimulation intensity rather than on various levels of anesthesia. Finally, we show that the electrodes provide recordings of the electrocorticogram (ECoG)

\footnotetext{
Abbreviations: 2P-LSM, two-photon laser scanning microscopy; CNS, central nervous system; Cre, Cre DNA recombinase; CreERT2, Cre DNA recombinase fused to mutated human estrogen receptor ligand-binding domain; CSCc, cathodic charge storage capacity; DAPI, 4',6-diamidino-2-phenylindole; ECoG, electrocorticogram; FI, fluorescence intensity; GFAP, glial fibrillary acidic protein; GFP, green fluorescent protein; GLAST, glutamate/aspartate transporter; Ibal, ionized calcium binding adaptor molecule 1; LCP, liquid crystal polymer; loxP, locus of crossover of the bacteriophage P1; NCX, $\mathrm{Na}^{+} / \mathrm{Ca}^{2+}$ exchanger; Nex, NeuroD6, subfamily of neuronal basic helix-loop-helix transcription factors; NMDA receptor, $\mathrm{N}$-methyl-d-aspartate receptor; pCAGGS, cytomegalovirus immediate early enhancer/chicken beta-actin/rabbit beta-globin hybrid promoter; PMCA, plasma membrane $\mathrm{Ca}^{2+}$ ATPase; ROI, region of interest; SD, standard deviation; SERCA, sarcoplasmic/endoplasmic reticulum $\mathrm{Ca}^{2+}$ ATPase; Th, Threshold; WPRE, Woodchuck hepatitis virus posttranscriptional regulatory element; Z, impedance.
} 
with a high signal-to noise ratio and spatial signal differences which help to decipher brain activity states during experimental procedures. Summarizing, the novel LCP surface micro-electrode is a versatile, convenient, and reliable tool to investigate brain function in vivo.

Keywords: liquid crystal polymer electrodes, cortical stimulation, electrocorticogram, in vivo two-photon laserscanning microscopy, neuron-glia interaction, astrocytes

\section{INTRODUCTION}

The perpetuate quest of understanding and modulating brain function continuously confronts the scientific community with a multitude of technical challenges (Rusakov, 2015; Chen et al., 2021). Neurons and their electrophysiological characteristics were the long-standing focus of brain research, promoting the development of various electrophysiological probes to record and/ or stimulate brain activity. Applications ranged from single cell experiments, over ex vivo slice measurements, to in vivo recording and stimulation from the surface or within the tissue. Electrical stimulation of the CNS is used in clinical routines to treat disorders such as Parkinson's disease by deep brain stimulation or depression by transcranial electrical stimulation (Kirsch and Nichols, 2013; Beudel and Brown, 2016; Beckner, 2020). The interaction of the electrical field and the excitable tissue is the base for artificial stimulation. When artificially triggering action potentials with electrical stimulation, the voltage-dependent conductivity of the cell membrane for $\mathrm{Na}^{+}$ (and $\mathrm{K}^{+}$) is exploited. The neuronal excitation depends on the applied field and cell orientation, neuronal subtype, cellular structure, as well as the resulting field distribution generated by the anisotropy of the neural tissue (Rattay, 1998; Basser and Roth, 2000; Radman et al., 2009; Ye and Steiger, 2015). However, advances in neuroscience established the essential contribution of glial cells to brain function in health and disease. Glial cells not only crucially maintain brain homeostasis, but actively participate in neurotransmission, shape neural circuits (Parpura et al., 1994; Araque et al., 1999; Verkhratsky and Nedergaard, 2018; Durkee and Araque, 2019; Caudal et al., 2020), act as resident immune-competent cells (Nimmerjahn et al., 2005; Prinz et al., 2019) and provide myelin sheaths, thereby ensuring fast and reliable neuronal communication (Simons and Nave, 2015; Swire and Ffrench-Constant, 2018). Moreover, glial cell (dys-) function has been implicated in a variety of CNS disorders including Alzheimer's (Gómez-Gonzalo et al., 2017; Arranz and De Strooper, 2019), Parkinson's (Yun et al., 2018; Guo et al., 2020), multiple sclerosis (International Multiple Sclerosis Genetics Consortium, 2019; Yeung et al., 2019; Traiffort et al., 2020) and epilepsy (Heuser et al., 2018; Nikolic et al., 2018; Deshpande et al., 2020). Importantly, glial cells such as astrocytes, primarily display activation through intracellular $\mathrm{Ca}^{2+}$ rises coupled to the release of neuroactive substances, modulating network function (Bazargani and Attwell, 2016; Covelo and Araque, 2018). In contrast, neurons are primarily characterized by their electrical activity but nonetheless exhibit extensive $\mathrm{Ca}^{2+}$ signaling relevant in physiology and pathology (Brini et al., 2014). In addition, neuron-glia interactions are governed by second messengers other than $\mathrm{Ca}^{2+}$, e.g., $\mathrm{Na}^{+}$(Ross et al., 2013; Karus et al., 2015; Ziemens et al., 2019) and cyclic AMP (Harada et al., 2017; Bernier et al., 2019). Investigation of those second messenger dynamics in vivo requires the use of fluorescent indicators and sensors, thus endorsing the refinement and novel development of neuroscientific tools to study neuron-glia interactions by combining electrophysiological and 2P-imaging techniques.

Considering combined electrophysiology and 2P-imaging in vivo (Figure 1A), the requirements for microelectrodes are ample (Chen et al., 2021). First and foremost, the electrode material must be biocompatible for chronic use, without mechanically damaging the tissue or eliciting inflammatory responses from glial cells. Along the same lines, the electrode array application should be minimally invasive and preferentially keep the dura mater intact (surface electrodes) without entailing major compromises on spatial resolution. Next, the electrode array should be either highly transparent (Park et al., 2014) or provide an optical window to perform imaging (multiphoton, coherent anti-stokes Raman spectroscopic microscopy etc.), potentially coupled to optogenetic approaches (Park et al., 2014; Xie et al., 2020). However, the biomaterial should be stable yet flexible for optimal tissue contact and withstand the impact of laser radiation during $2 \mathrm{P}$-imaging without excessive heat generation. From an electrochemical point of view, the electrodes should be optimized, providing low impedance and high current transfer capability (Cogan, 2008). Finally, the fully assembled microelectrode should allow a safe, fast, and reproducible application in common (rodent) model organisms and come at an affordable cost.

Polyimide (PI) and LCP are the most common flexible carrier materials of industrial large-scale production. Their electrical properties in combination with their chemical and mechanical strength make both materials good candidates for microelectrode assemblies, with LCP electrodes being significantly less expensive than PI electrodes (Woods et al., 2018). Here, we developed LCP electrodes of a stacked support structure formed by Ultralam 3850 sheets and Ultralam 3908 bonding film (Rogers Corporation; Woods et al., 2018). Such LCP material has also been used to record acute neuronal activity in humans (Chiang et al., 2021), indicating its high biocompatibility.

\section{MATERIALS AND METHODS}

\section{Electrode Technology}

The electrodes were designed based on triple LCP layers (Dyconex AG, Switzerland) allowing flexibility, yet maintaining stability, while the electrical circuit structure was made of a 
A

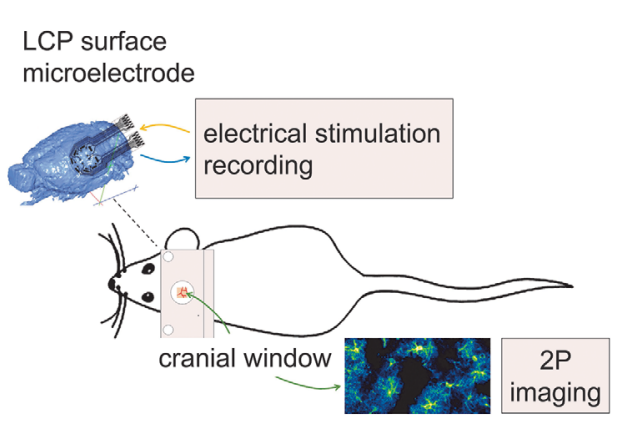

B

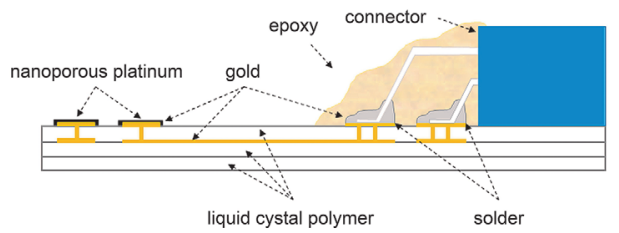

C

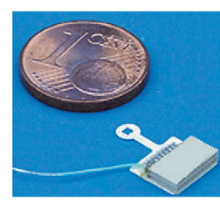

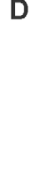

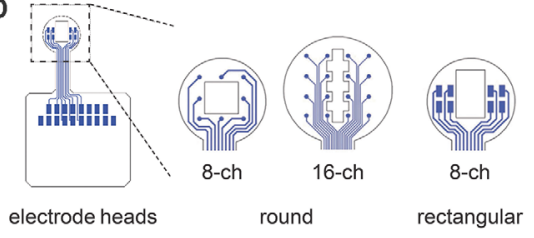

E
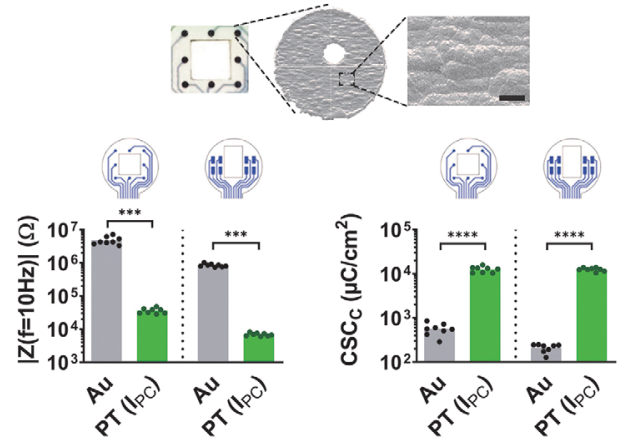

FIGURE 1 | Development of liquid crystal polymer (LCP) surface electrodes for in vivo studies combining electrophysiology and imaging. (A) Flexible yet robust surface microelectrodes, applicable for in vivo investigation of electrical brain stimulation, electrocorticographic recording of brain activity, and $2 \mathrm{P}$-imaging of $\mathrm{Ca}^{2+}$ signals. (B) Electrode structure with an LCP base including golden electrical structure and superficial gold electrodes, electroplated with nanoporous platinum. The nano-connector is soldered to the terminal pads and secured with epoxy resin. (C) Fully assembled LCP surface microelectrode. (D) Three different electrode arrays with eight or 16 circular electrodes ( $3 \mathrm{~mm}$ or $4 \mathrm{~mm}$ in diameter) for ECoG recording or eight rectangular electrodes for stimulation. Circular electrode sites are 150 $\mu \mathrm{m}$ in diameter; the size of rectangular-shaped sites is $400 \mu \mathrm{m} \times 200 \mu \mathrm{m}$. The two 8-channel electrode configurations have a spare square in the center ( $1 \mathrm{~mm} \times 1 \mathrm{~mm}$ or $1 \mathrm{~mm} \times 1.5 \mathrm{~mm}$ ), the 16-channel electrode has a polygon (length $2.8 \mathrm{~mm}$; small width: $400 \mu \mathrm{m}$; large width: $800 \mu \mathrm{m}$ ), allowing 2P-imaging. (E) Top: scanning electron micrograph of a single electrode site showing the surface structure, scale bar $=5 \mu \mathrm{m}$. Bottom: typical magnitude of electrode impedance at a frequency of $10 \mathrm{~Hz}(|Z(f=10 \mathrm{~Hz})|)$ and typical cathodic charge storage capacity $\left(C S C_{C}\right)$. Compared with the gold electrode sites, platinum-coated sites display a lower impedance enabling recordings with less noise and a higher $\mathrm{CSC}_{C}$ allowing for higher stimulation currents. Statistics: $|\mathrm{Z}(f=10 \mathrm{~Hz})|:$ Mann-Whitney test and $\mathrm{CSC}_{\mathrm{C}}$ : unpaired $t$-test ${ }^{* * *} p<0.001,{ }^{* * * *} p<0.0001 . N=8$ measurements per condition.

double gold layer (Figure 1B). The LCP structure had a thickness of about $75 \mu \mathrm{m}$, a limitation in the minimum electrode site size of about $100 \mu \mathrm{m}$, and an interconnection width of about $30 \mu \mathrm{m}$. The PCB layout program EAGLE (version 7.5.0 Light; CadSoft) was used to generate the electrode geometry and electrical layout, which was sent to the manufacturer for large-volume industrial production. Epoxy resin (TC-EP05-24, TOOLCRAFT) was used to cover the connector (NPD-18-18AA-GS, Omnetics Connector Corp.) and pads. The gold electrode sites were coated with galvanized nanoporous platinum (5 g hexachloroplatinic acid dissolved in $375 \mathrm{ml}$ distilled water; pulse electroplating at $0.3 \mathrm{kA} / \mathrm{m}^{2}, 90$ pulses) and electrochemically characterized by determining the electrode impedance and the cathodic charge storage capacity $\left(\mathrm{CSC}_{C}\right.$; Cogan, 2008) with the multi-chemistry device Gamry Interface 1000 (Gamry Instruments).

\section{Epidural Electrode Implantation and Cranial Window Surgery}

Animals were anesthetized with a mixture of $2 \%$ Isoflurane with $\mathrm{O}_{2}(0.6 \mathrm{~L} / \mathrm{min})$ and $\mathrm{N}_{2} \mathrm{O}(0.4 \mathrm{~L} / \mathrm{min})$ and kept on a heating plate. A standard craniotomy (3-4 $\mathrm{mm}$ in diameter; Cupido et al., 2014; Kislin et al., 2014) was performed over the somatosensory cortex and the surface electrode was placed on the dura mater before applying the glass coverslip. A ground electrode (platinum wire) was superficially inserted into the cerebellar vermis and fixed to the skull surface with dental cement. Electrodes, glass coverslips, and platinum wire were disinfected and cleaned with alcohol (70\% ethanol) and distilled water. Finally, a 3D-printed custom-made holder for head restraining was applied and all components were fixed with dental cement.

\section{In vivo Two-Photon Laser Scanning Microscopy (2P-LSM)}

Images were acquired on a custom-made 2P-LSM setup with a mode-locked Ti:Sapphire laser (Vision II, Coherent) using ScanImage software (Pologruto et al., 2003). 2P-LSM settings: laser power $30-50 \mathrm{~mW}$; frame rate of $1.9 \mathrm{~Hz}$ [field of view (FOV) size $256 \mu \mathrm{m} \times 256 \mu \mathrm{m}$ ) or $3.3 \mathrm{~Hz}$ (FOV size $256 \mu \mathrm{m} \times 256$ $\mu \mathrm{m}$ ); pixel size: $0.5 \mu \mathrm{m} \times 0.5 \mu \mathrm{m}$; astroglial $\mathrm{Ca}^{2+}$-transients were acquired in cortical layer I $(40 \mu \mathrm{m}-90 \mu \mathrm{m})$ and neuronal activity in layer II/III $\left(180 \mu \mathrm{m}-210 \mu \mathrm{m}\right.$. Prior to $\mathrm{Ca}^{2+}$ imaging, animals were habituated according to adapted protocols without water restriction (Guo et al., 2014; Kislin et al., 2014). During imaging, the animals were head-fixed and anesthesia was delivered via a breathing mask [0-2.5\% isoflurane with $\mathrm{O}_{2}(0.6 \mathrm{~L} / \mathrm{min})$ and $\mathrm{N}_{2} \mathrm{O}$ $(0.4 \mathrm{~L} / \mathrm{min})]$.

\section{Automated Detection of Spontaneous $\mathrm{Ca}^{2+}$ Events}

$\mathrm{Ca}^{2+}$-event analysis was performed using a custom-made analysis software based on MATLAB (MSparkles, unpublished). First, the fluorescence range of each pixel along the temporal 
axes of the image stack was computed. Next, local maxima within the range projection were used as seed points for simultaneous, correlation-based region growing. Thereby, the temporal correlation of a candidate pixel with the corresponding seed point was computed using Pearson's linear correlation coefficient. A user-definable correlation threshold was set as the stopping criterion of the region growing process in case the temporal evolution of a candidate pixel deviated too strongly from its respective seed point. A pixel-based correlation coefficient maximization algorithm was employed for image registration (Evangelidis and Psarakis, 2008) and to reduce small motion artifacts of the acquired time series. Upon ROI integration (computing the mean fluorescence per ROI per image), properties of $\mathrm{Ca}^{2+}$ transients were obtained using the MATLAB function findpeaks().

\section{Electrocorticographical Recording}

A 16-channel biosignal amplifier (g.USBamp, g.Tec medical engineering) with a preamplifier (g.HEADstage, gTec medical engineering) and a custom made control software based on MATLAB/Simulink (Englert et al., 2017) was used to acquire the electrical biosignals at a channel sampling rate of $1.2 \mathrm{kHz}$. Filtering was chosen with a band pass filter of $0.5 \mathrm{~Hz}$ to $250 \mathrm{~Hz}$ and a notch filter of $50 \mathrm{~Hz}$. Signal processing was performed by calculating the short-time Fourier transform (rectangular sliding window of $2 \mathrm{~s}$ shifted in steps of $1 \mathrm{~s}$ ) and by calculating the correlation coefficient between all single recording channels with customized MATLAB scripts using the main functions spectrogram() and corr(), respectively. ECoG sections of $30 \mathrm{~s}$ from awake and anesthetized mice were used to calculate channel correlation and analyzed as a function of electrode distances. In addition, the channel correlation was calculated with a rectangular sliding window of $2 \mathrm{~s}$ in steps of $1 \mathrm{~s}$.

\section{Electrical Stimulation}

A single channel stimulator (ISO-STIM 01D, NPI electronic) connected via a digital-to-analog output card (NI PCI-6723, National Instruments) was controlled by a customized control software (LabView, National Instruments). A second output channel of the analog output card was used for synchronization with the $2 \mathrm{P}$-microscope. The output sampling rate was set to $100 \mathrm{kHz}$. Threshold (Th) definition was performed in anesthetized animals (isoflurane concentration 1.5\%) at $50 \mathrm{~Hz}$ stimulation frequency by increasing stimulation current intensities in steps of $25 \mu \mathrm{A}$ (starting at $100 \mu \mathrm{A}$ ) for 300 frames (approximately $90 \mathrm{~s}$ ). Threshold values typically ranged from $125-200^{\circ} \mu \mathrm{A}$. Subsequently, we applied two stimulations at Th, $\mathrm{Th}+50 \mu \mathrm{A}, \mathrm{Th}+100 \mu \mathrm{A}$ to quantify the $\mathrm{Ca}^{2+}$-responses. For signal analysis, the mean value per statistical parameter of both stimulation per current strength was calculated. The stimulation series was applied to anesthetized (isoflurane concentrations: $1.5 \%, 1 \%, 0.5 \%$ ) and awake (isoflurane concentrations: $0 \%$ ) mice.

\section{Detection of Electrically Evoked $\mathrm{Ca}^{2+}$ Events}

Custom-made MATLAB scripts were used to analyze the $\mathrm{Ca}^{2+}$ events in neurons and astrocytes. A pixel-based correlation algorithm to align individual images was employed for stack registration (Evangelidis and Psarakis, 2008) followed by the calculation of the mean fluorescence intensity of the whole individual gray-scale images [MATLAB function mean()]. Peak amplitude $\left(F-F_{0} / F_{0}\right)$, delay to peak, given as time from $10 \%$ of peak amplitude (rising signal) to peak amplitude, and signal duration, given as time from $10 \%$ to $10 \%$ of peak amplitude, were determined as parameters of the transient signals. Only $\mathrm{Ca}^{2+}$ events that followed from electrical stimulation were considered.

\section{Immunohistochemistry}

Animals were perfused intracardially with PBS and 4\% formaldehyde. Dissected brains were subsequently post-fixed overnight at $4^{\circ} \mathrm{C}$. Free-floating coronal vibratome slices $(40 \mu \mathrm{m})$ were generated (VT1000S, Leica, Biosystems, Wetzlar, Germany) and sections were collected, blocked, and permeabilized (blocking solution, $0.5 \%$ Triton X-100 and 5\% horse serum in PBS) for $1 \mathrm{~h}$ at RT. The slices were incubated with primary antibodies diluted in blocking solution overnight, at $4^{\circ} \mathrm{C}$. After washing with PBS, the slices were incubated with fluorescent secondary antibodies diluted in blocking solution for $2 \mathrm{~h}$ at RT. DAPI $(0.025 \mu \mathrm{g} / \mathrm{ml}$ final concentration $)$ was added to the secondary antibody solutions to stain nuclei. The primary antibodies were used as follows: goat anti-GFP (1:1,000, Rockland, Limerick, PA, USA), mouse anti-GFAP (1:500, Novocastra, Leica Biosystems, Wetzlar, Germany) and rabbit anti-Iba1 (1:500, Wako, Osaka, Japan). Stained slices were scanned with the fully automated epifluorescence slide scanner microscope AxioScan.Z1 (Zeiss, Oberkochen, Germany) and analyzed with the ZEN imaging software (Zeiss). Cortical areas $\left(3.92 \pm 0.32 \mathrm{~mm}^{2}\right)$ on both hemispheres of the slices were selected for analysis of the fluorescence intensities. The same area size was used for all stainings of one slice.

\section{Statistics}

Statistical analysis was performed with GraphPad Prism 8. Data distributions were assessed with the Shapiro-Wilk normality test. In the case of normal distribution, single comparisons were computed with parametric unpaired $t$-tests and multiple comparisons with two-way ANOVA (mixed model) followed by Tukey's post hoc test. When data were not normally distributed, we applied a non-parametric Mann-Whitney test for single comparisons and Kruskal-Wallis test followed by Dunn's post hoc test for multiple comparisons.

\section{Animals}

Mice were maintained in the animal facilities of the Centre for Integrative Physiology and Molecular Medicine (CIPMM, University of Saarland). Mice received food ad libitum. Knockin

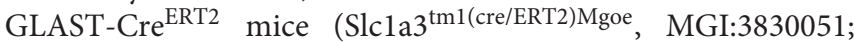

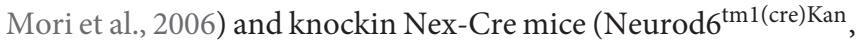
MGI: 2668659) were crossbred to mice with Rosa26 reporter

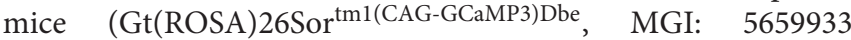
(Paukert et al., 2014). For in vivo 2P-LSM, ECoG recording, stimulation experiments, and IHC, 12-17 week old mice were studied. To induce reporter expression in 8 week old transgenic GLAST-Cre $\mathrm{ERT2}^{\mathrm{E}}$ mice, animals received tamoxifen 
intraperitoneally (10 $\mu \mathrm{g} / \mathrm{ml}, 100 \mu \mathrm{l} / 10 \mathrm{~g}$ body weight) once per day for five consecutive days (Jahn et al., 2018).

\section{Ethics Statement}

Animal experiments were carried out at the University of Saarland according to European and German guidelines and approved by "Landesamt für Gesundheit und Verbraucherschutz" of Saarland state (license numbers: 71/2013, 36/2016).

\section{RESULTS}

\section{Surface Electrode Arrays for Electrical Stimulation and ECoG Recording Enclosing an Optical Window}

Our aim was to develop microelectrodes, applicable for in vivo measurements of electrical brain stimulation as well as the electrocorticographic recording of brain activity coupled to 2P-imaging in the region of interest (Figure 1A). Thereby, minimizing electrode effects on the tissue is pivotal for the functional assessment of complex network interactions. To avoid cellular responses associated with penetrating electrodes (Burda et al., 2016; Sohal et al., 2016; Donat et al., 2017), three different LCP surface electrodes were developed to be placed on the dura, enabling stimulation and recording of the brains' electrical activity (Figure 1A). The electrode base consists of a triple layer of white LCP, accommodating the two-layered golden electrical structure. The inner gold layer served as an interconnection plane, the outer layer harbors the electrode sites and solder pads. Electrode sites were electroplated with nanoporous platinum. An 18-pin nano-connector was soldered to the terminal pads and fixed by epoxy resin (Figure 1B).

Each electrode can potentially be used for stimulation and recording. Here, we used preferentially an eight-channel model with circular electrode sites (diameter $=150 \mu \mathrm{m}$ ) arranged in a three-by-three matrix (center-center distance: $750 \mu \mathrm{m}$ ) with sparing the center, for recordings (Figures 1C,D, rec) and an eight-channel model with rectangular electrodes sites $(400 \mu \mathrm{m} \times 200 \mu \mathrm{m})$ arranged in two groups of four for stimulation (Figure 1D, stim). The round electrode diameter was $3 \mathrm{~mm}$ and both electrodes contained a central window for 2P-LSM (size: $1 \mathrm{~mm} \times 1 \mathrm{~mm}$ or $1 \mathrm{~mm} \times 1.5 \mathrm{~mm}$ respectively; Figures 1C,D). In addition, a 16-channel electrode with roundshaped sites $($ diameter $=150 \mu \mathrm{m}$; center-center distance $=750$ $\mu \mathrm{m}$; arranged in a four-by-four matrix) was developed for the acquisition of electrocorticograms (ECoGs) over a larger cortical region. The optical window of the electrode has a polygonal shape (length $2.8 \mathrm{~mm}$; small width: $400 \mu \mathrm{m}$; large width: 800 $\mu \mathrm{m}$; Figure 1D). The distance between electrode sites and optical window, as well as the sizes of round electrode sites were chosen in accordance with the manufacturer's minimum recommendations. The catwalk of each electrode array had a length of $3 \mathrm{~mm}$ and a width of $1.1 \mathrm{~mm}$ and allowed the placement of the electrode within the craniotomy. The pad area accommodating the connector was $8.2 \mathrm{~mm} \times 7.4 \mathrm{~mm}$. Prior to covering the connector with epoxy resin, an additional wire was soldered to the electrode connector enabling the use of an additional ground electrode (Figure 1C).

After platinum electroplating of the electrode sites (Figure 1E), the impedance magnitude at a frequency of $10 \mathrm{~Hz}$ was reduced from $3.3 \mathrm{M} \Omega-7.2 \mathrm{M} \Omega$ to $29 \mathrm{k} \Omega-48 \mathrm{k} \Omega$ for the round-shaped sites and $740 \mathrm{k} \Omega-1 \mathrm{M} \Omega$ to $6 \mathrm{k} \Omega-8.2 \mathrm{k} \Omega$ for the rectangular-shaped sites. This resulted in lower noise (Obien et al., 2014) and a lower voltage drop during stimulation. The cathodic charge storage capacities, as a comparable measure of stimulation current drive capability, were increased from 420 $\mu \mathrm{C} / \mathrm{m}^{2}$ to $550 \mu \mathrm{C} / \mathrm{m}^{2}$ to $10,500 \mu \mathrm{C} / \mathrm{cm}^{2}$ to $15,800 \mu \mathrm{C} / \mathrm{cm}^{2}$ (round electrode sites) and from $130 \mu \mathrm{C} / \mathrm{m}^{2}$ to $250 \mu \mathrm{C} / \mathrm{m}^{2}$ to $10,500 \mu \mathrm{C} / \mathrm{m}^{2}$ to $14,000 \mu \mathrm{C} / \mathrm{m}^{2}$ (Figure 1E). The rectangular electrode sites can either be used in single electrode configuration for a higher stimulation selectivity or connected together for generating a broader and more uniform current distribution.

\section{LCP Surface Electrodes Are Highly Biocompatible and Even Stabilize the Tissue After Cranial Window Surgery}

Reactive astrocytes and microglia are primary and reliable indicators of CNS inflammation at different time scales. While microglia respond rapidly, within minutes to hours, astrocytes are activated after a couple of days. After an acute insult of sufficient magnitude or continuous inflammatory processes, both cell types contribute to the development of gliosis (glial scar; Burda and Sofroniew, 2014). Considering that chronic in vivo experiments usually start after several days of recovery, we investigated the biocompatibility of the LCP surface electrodes in transgenic mice with astroglial GCaMP3 expression (Figure 2A) 3 days (for acute responses) and 28 days (for chronic responses) post-implantation (Figure 2B). LCP surface electrodes were implanted after a standard craniotomy, covered with a glass coverslip, and histological outcomes were compared to sham-treated mice that only underwent cranial window surgery (Figure 2B).

Cortical cell responses were assessed by fluorescence intensity (FI) analysis of immunohistochemical markers for microglia (Iba1) and reactive astrocytes (GFAP; Figure 2C). The density of recombined astrocytes was assessed by immunodetection of GCaMP3 using GFP antibodies. The general cell density was visualized by nuclear DAPI staining. No alterations of cortical layer structures were detected in either group at any time point (Figure 2C). Ipsilateral FI values normalized to the contralateral side showed that neither the surgery nor the electrode itself changed expression levels of DAPI, GFP, or Ibal at three or 28 days post-surgery (FI normalized to contra $\approx 1$, Figures 2 C,D). In contrast, GFAP levels in sham operated animals tripled compared to the contralateral side as well as compared to electrode-implanted animals at both three (FI normalized to contra $=3.4$ ) and 28 days post-surgery (FI normalized to contra $=3.2, p=0.031$; Figures 2C,D). Animals carrying the LCP surface electrode displayed a slight GFAP increase 3 days post-surgery (FI normalized to contra $=1.4$ ) that was negligible 28 days post-surgery (FI normalized to contra $=1.2$; Figure 2D). We concluded that the LCP surface 
A

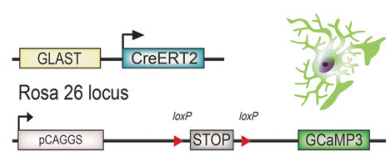

B

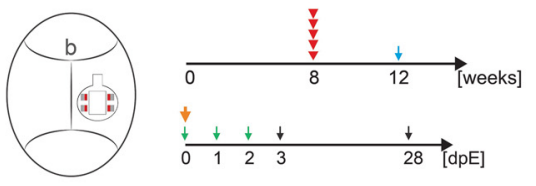

(19:) cranial window with electrode tamoxifen

b bregma surgery post-OP car
analysis
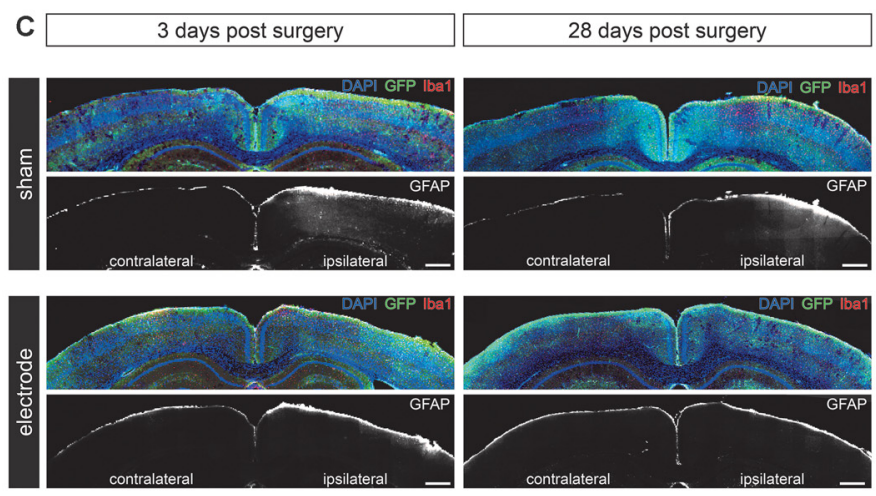

D

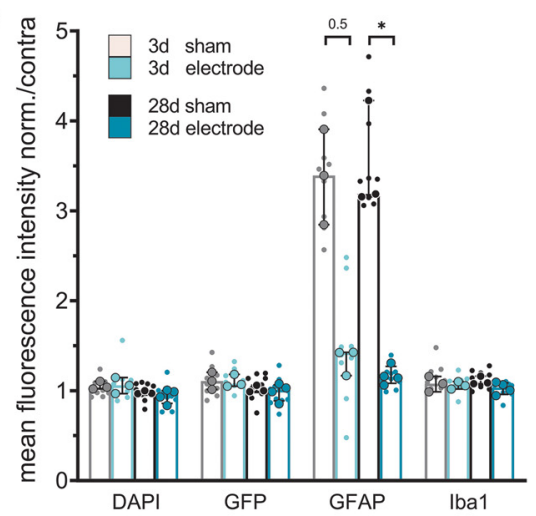

FIGURE 2 | LCP surface electrodes are long-term biocompatible and favorable for in vivo studies. (A) The biocompatibility study was carried out on transgenic mice with tamoxifen-induced, astrocyte-specific GCaMP3 expression. (B) Eight-week-old animals were administered five consecutive i.p. injections of tamoxifen to induce GCaMP3 expression in astrocytes. At 12 weeks of age, animals underwent cranial window surgery with or without (sham) surface electrode implantation. An immunohistochemical analysis was carried out 3 or 28 days post-surgery. (C) Activation of microglia (Iba1) and astrocytes (GFAP) was assessed by immunohistochemical staining of coronal slices. GCaMP3 expression was revealed by GFP immunostaining. Ipsilateral: surgery side, contralateral: control side. Scale bars indicate $500 \mu \mathrm{m}$. (D) Astroglial GFAP reactivity was increased in sham groups compared to electrode implanted groups both 3 and 28 days post-surgery, while the astrocyte activation of the electrode implanted groups was only minimally increased, indicating high biocompatibility and an additional stabilizing effect of the LCP cortical surface electrode. Ipsilateral fluorescence intensity values were normalized to the contralateral side. Statistics: Kruskal-Wallis test followed by Dunn's multiples comparisons test ${ }^{*} p<0.05$. Data are displayed as median with IQR. Larger data points correspond to the average of slices from the same animal, smaller data points indicate individual slices. $3 \mathrm{~d}$ sham $N$ (animal) $=3, n$ (slice) $=9 ; 3$ d electrode $N=3, n=9 ; 28 d$ sham $N=3, n=9 ; 28 d$ electrode $N=4, n=12$.

electrode did not elicit significant activation of microglia or astrocytes at an acute or chronic time scale. In fact, the electrode had an alleviating effect on cortical glia activation compared to the simple cranial window surgery, suggesting an additional stabilizing effect.

\section{Electrical Stimulation Synchronized With In vivo $2 \mathrm{P}-\mathrm{Ca}^{2+}$ Imaging Reveals Stimulation Intensity and Anesthesia-Dependent Biphasic Neuronal $\mathrm{Ca}^{2+}$-Signal Signature}

Electrical stimulations were performed in Nex-Cre $\times$ GCaMP3 mice (Figure 3A) at different isoflurane concentrations to investigate how anesthesia could affect the $\mathrm{Ca}^{2+}$ response of neuronal networks. The surface electrode with rectangular-shaped sites was used (Figure 3A, stim). The influence of the imaging position with reference to the electrode sites was minimized by simultaneously using the two inner electrode sites left and right of the observation window to apply an electrical current. Layer II/III of the cortex were recorded by $2 \mathrm{P}-\mathrm{LSM}$ at a depth of $180 \mu \mathrm{m}-210 \mu \mathrm{m}$. Threshold (Th) definition was performed in anesthetized animals at $50 \mathrm{~Hz}$ stimulation until a large $\mathrm{Ca}^{2+}$ wave was induced. Subsequently, two $50 \mathrm{~Hz}$ stimulations at $\mathrm{Th}, \mathrm{Th}+50 \mu \mathrm{A}$, Th $+100 \mu \mathrm{A}$ were applied to study the elicited $\mathrm{Ca}^{2+}$ responses.
The stereotypical neuronal $\mathrm{Ca}^{2+}$ waves could be elicited across all levels of anesthesia (Figures 3B,C). Under lower anesthesia $(\leq 0.5 \%)$, two peaks became apparent in the $\mathrm{Ca}^{2+}$ transients, after extracting the image brightness (Figure 3C). The sources of these peaks were estimated from the short image series of every second 2P-LSM image (Figure 3B). The image at time $0 \mathrm{~s}$ was set as the image directly at stimulation onset. Two frames later $(1.17 \mathrm{~s})$, the activation of the neuropil was clearly visible (first peak in the $\mathrm{Ca}^{2+}$ transients in Figure 3C(1)), before the somata were activated (second peak, Figure 3C(2)). The response of the neuropil did not show any dependence on the anesthesia level or stimulation amplitude (Figure 3D). In contrast, the somatic $\mathrm{Ca}^{2+}$ transient amplitude varied with isoflurane and strongly depended on the stimulation intensity (Figure 3E). The delay times (mean $\pm \mathrm{SD}$ ) from stimulation onset to maximum image intensities (peak) were rather constant for all measurements (delay peak I: $0.86 \mathrm{~s} \pm 0.13 \mathrm{~s}$; delay peak II: $2.34 \mathrm{~s} \pm 0.16 \mathrm{~s}$; Figures 3F,G). The duration of the $\mathrm{Ca}^{2+}$ signal including neuropil and somata was $3.63 \mathrm{~s} \pm 0.24 \mathrm{~s}$ and did not respond to the variations of isoflurane or stimulation amplitude (Figure $3 \mathbf{H}$ ). After each stimulation, an undershoot of fluorescence intensity occurred (Figure 3C(3)). The undershoot duration decreased from $57.4 \mathrm{~s} \pm 5.5 \mathrm{~s}$ to $33.5 \mathrm{~s} \pm 3.0 \mathrm{~s}$ with decreasing anesthesia level, but was independent of the stimulation strength (Figure 3I). 


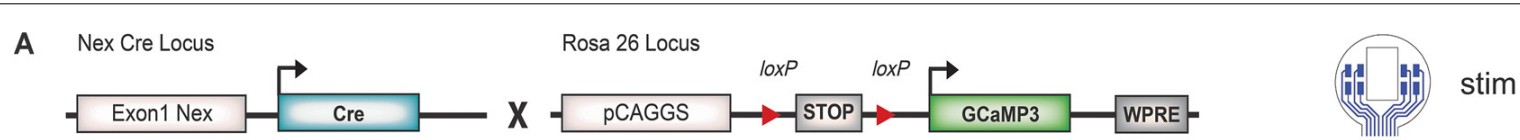

B

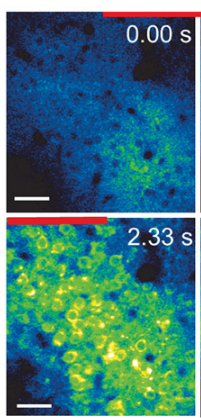

D

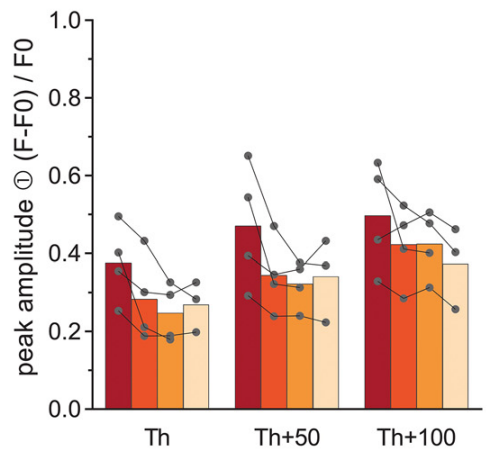

E

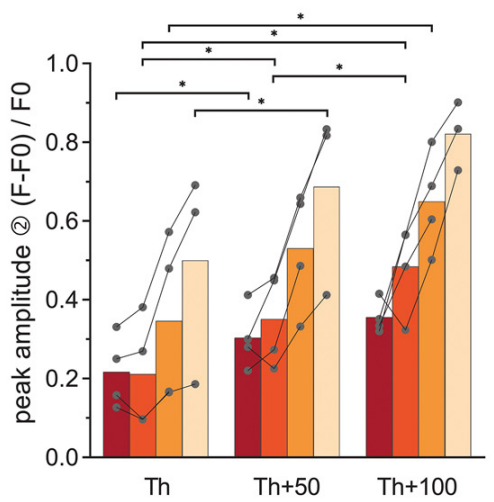

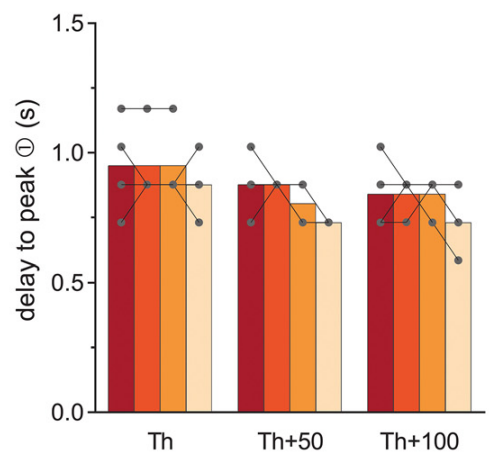

G

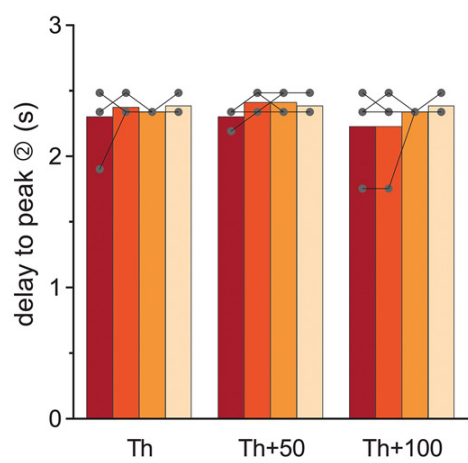

H

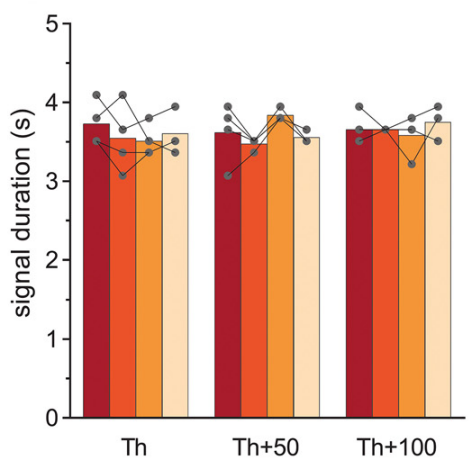

I

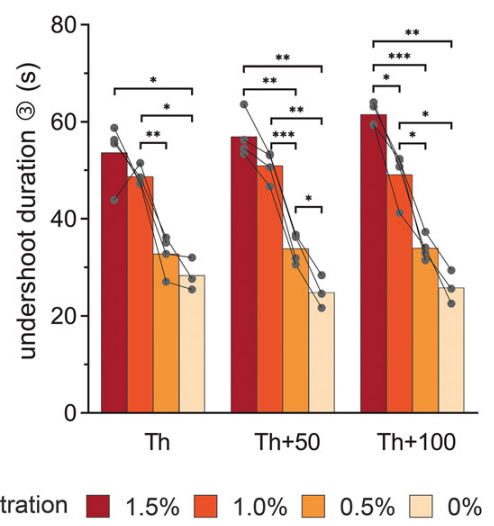

FIGURE 3 | Simultaneous electrical stimulation and in vivo 2P-Ca ${ }^{2+}$ imaging reveals the stimulation intensity- and anesthesia-dependent neuronal Ca ${ }^{2+}$-signal signature. (A) Transgenic mice expressing the $\mathrm{Ca}^{2+}$ sensor GCaMP3 in cortical neurons were used for stimulations with the 8-channel stimulation electrode. (B) $2 \mathrm{P}-\mathrm{Ca}^{2+}$ imaging sequence during electrical stimulation (red bar). The first $\mathrm{Ca}^{2+}$ response originates from the neuropil (0-1.17 $\left.\mathrm{s}\right)$ and was followed by transient somatic signals (1.75-3.5 s), scale bar $=40 \mu \mathrm{m}$. (C) Top row: neuronal $\mathrm{Ca}^{2+}$ peaks in response to electric stimulation (red bar) are systematically followed by an undershoot (3) at all isoflurane concentrations (1.5-0\%), scale bar = $15 \mathrm{~s}$. Bottom row: at higher temporal magnification, a biphasic peak (1, 2) was reliably observed at isoflurane concentrations $\leq 0.5 \%$. (D) The amplitude of the first neuronal $\mathrm{Ca}^{2+}$ peak component was independent of stimulation intensity and anesthesia level. (E) The amplitude of the second peak component was potentiated with increasing stimulation intensities. (F) The delay between the stimulation onset and the local maximum of the first peak component did not change with stimulation intensity or anesthesia level. (G) The delay between the stimulation and the local maximum of the second peak component remained unchanged with varying stimulation intensity or anesthesia level. (H) $\mathbf{C a}^{2+}$ peak duration did not vary with stimulation intensities and isoflurane concentrations. (I) Duration of the undershoot following the biphasic peak was strongly dependent on the level of anesthesia, with approximately 50\% shorter durations in awake animals compared to 1.5\% isoflurane anesthesia, across stimulation protocols. Statistics: Two-Way ANOVA (mixed model) followed by Tukey's multiple comparisons test * $p<0.05,{ }^{* *} p<0.01$, ${ }^{* * *} p<0.001$, for isoflurane $1.5-0.5 \% N=4$ and isoflurane $0 \% N=3$ measurements per stimulation intensity. Th: threshold. 


\section{Evoked Astroglial $\mathrm{Ca}^{2+}$ Signals Display Stimulation Intensity-Dependent Characteristics}

Electrical stimulations were also performed in GLASTCre ${ }^{\text {ERT2 }} \times$ GCaMP3 mice to study the response of astrocytes (Figure 4A). The stimulation procedure was chosen as described above (different levels of isoflurane concentration: $1.5 \%$, $1.0 \%, 0.5 \%$, and $0 \%$; electrode with rectangular-shaped sites (Figure 4A, stim), the inner electrode sites were electrically connected; $50 \mathrm{~Hz}$ stimulation; 100 pulses). 2P-LSM recordings were performed in layer I of the cortex at a depth of $40 \mu \mathrm{m}-90$ $\mu \mathrm{m}$. Threshold (Th) definition was performed in anesthetized animals at $50 \mathrm{~Hz}$ stimulation until a $\mathrm{Ca}^{2+}$ wave was visible. Subsequently, we applied $50 \mathrm{~Hz}$ stimulations at Th, Th $+50 \mu \mathrm{A}$, $\mathrm{Th}+100 \mu \mathrm{A}$ to study the elicited $\mathrm{Ca}^{2+}$ responses.

$\mathrm{Ca}^{2+}$ transients in cortical astrocytes (somata and processes) could be provoked by electrical stimulation at all levels of anesthesia (Figures 4B,C). In general, astrocytes responded stronger to the stimulation amplitude rather than isoflurane concentration. The astroglial peak amplitudes (Figure 4D) showed an increase from $\mathrm{Th}$ to $\mathrm{Th}+50 \mu \mathrm{A}$, while the $\mathrm{Ca}^{2+}$ signal amplitude was rather constant from $\mathrm{Th}+50 \mu \mathrm{A}$ to $\mathrm{Th}+100 \mu \mathrm{A}$. However, the amplitude values showed high variability. The peak of the astrocytic $\mathrm{Ca}^{2+}$ related signals was detected after the end of the stimulation (Figure 4E). There was a slight reduction in the delay time from stimulation onset until the maximum was reached with increasing stimulation intensity. For the highest stimulation current, the delay time was approximately within $3.5 \mathrm{~s}$ to $5 \mathrm{~s}$ and for the lowest stimulation current approximately $3.5 \mathrm{~s}$ to $5.5 \mathrm{~s}$. The delay time from stimulation onset to the $\mathrm{Ca}^{2+}$ transient rise (10\% of maximum) was decreased by the duration of 1 to 2 imaging frames ( $300 \mathrm{~ms}$ to $600 \mathrm{~ms}$ ) with increasing stimulation strength (Figure 4F). No significant difference in the duration of the $\mathrm{Ca}^{2+}$ transient was visible, neither with the stimulation amplitude nor with the depth of anesthesia (Figure 4G).

\section{Recordings With the LCP Electrode Arrays Showed a High Signal-to-Noise Ratio and Spatial Signal Differences Reflecting the Brains' Activity States}

The 16-channel electrode was used to evaluate the recording quality and to assess the spatial distribution of signal events. The depth of anesthesia was modulated (isoflurane $1.5 \%$ to $0 \%$ ) to vary the pattern of the bioelectrical activity (Land et al., 2012). The recordings showed a typical synchronous burst activation of neurons when the mice were anesthetized (Figure 5A). With decreasing anesthesia, the time between the bursts became shorter and the signal amplitude lower, indicating a loss of synchrony. When the mouse was awake, the burst pattern was no longer visible. The difference in neuronal activity was also visible in the spectrograms of the signals (Figure 5B). In the anesthetized mouse, the highest signal intensities were at frequencies below $10 \mathrm{~Hz}$, and frequencies higher than $30 \mathrm{~Hz}$ were temporarily visible when the neurons fired synchronously. Since there was no evidence of signal components with a broad frequency range during the burst suppression phases, we concluded that there was no detectable noise affecting the signal quality. In the awake state, the highest signal intensity was also below $10 \mathrm{~Hz}$, but the higher frequencies were always present due to the continuous spiking activity (Figure 5B).

The individual time of signal traces showed a high similarity between the individual channels (Figure 5A). To characterize the channel similarity, the correlation between the recorded signals was calculated. A stepwise calculation (sliding window of $2 \mathrm{~s}$, step time $0.5 \mathrm{~s}$ ) demonstrated the dependency on the synchrony of cortical electrical activity (Figure 5C). The channel similarity was lower if there was high spike activity (bursts and neuronal activity in the awake state). In addition, the correlation decreased with channel distance. Correlations were calculated for $30 \mathrm{~s}$ traces in relation to the distance of the electrode sites (Figure 5D). The distances of the electrode sites are given as normalized geometric distances (value of 1 means the electrode center-center distance of $750 \mu \mathrm{m}, 1.41$ means $1057.5 \mu \mathrm{m}$, etc.). This diagram confirms the results from the stepwise calculation. The correlation coefficient was high for electrode sites nearby and decreased with increasing distance. For awake mice, the correlation was constantly lower than for mice under anesthesia. The variation within one electrode distance resulted from the different signals in the single recordings and from the various channel pairs. At electrode distance 0 , the result of the correlation of the channels with themselves is given.

\section{Stable Long-Term Recordings of Electrophysiological and Spontaneous Astroglial $\mathrm{Ca}^{2+}$ Signals in the Mouse Cortex}

To demonstrate the functionality of the combination of in vivo ECoG recording and $\mathrm{Ca}^{2+}$ events by $2 \mathrm{P}-\mathrm{LSM}$, an eight-channel electrode was implanted in a GLAST-Cre ${ }^{\text {ERT2 }} \times$ GCaMP3 mouse (Figure 6A). The depth of anesthesia was varied in an arbitrarily selected variation of isoflurane from $2.5 \%$ to $0 \%$ (orange stars in Figure $6 \mathrm{E}$ ) to change the activity state, and thus the activity of neurons and astrocytes. We could achieve high-quality 2P-LSM and ECoG recordings over a long recording period ( $>30 \mathrm{~min}$ ) and up to 35 days after electrode implantation. The cranial window quality allowed clear visibility of astroglial somata, processes, and $\mathrm{Ca}^{2+}$ transients (Figure 6B). The 2P-LSM images were processed with the MATLAB based tool MSparkles to find activity-based regions of interest (ROIs; Figure $6 \mathrm{C}$ ), calculating the signal amplitudes $\left[(F-F 0) / F 0\right.$; Figure 6D] and to classify the $\mathrm{Ca}^{2+}$ events in small ( $1 \mathrm{SD} \leq$ signal amplitude $<2 \mathrm{SD})$, medium (2 SD $\leq$ signal amplitude $<3 \mathrm{SD}$ ), and large signals ( $3 \mathrm{SD} \leq$ signal amplitude; Figure 6E). The standard deviation (SD) referred to the base fluorescence F0. The activity of the astrocytes increased with decreasing anesthesia which is in line with previous reports of other groups (Thrane et al., 2012; Bojarskaite et al., 2020).

To obtain a more comprehensive overview of the responses in a given field-of-view, the signal classification from the different ROIs was summed up within a time step of $30 \mathrm{~s}$ and the normalized FI, as well as the correlation of subsequent images, was calculated (Figure 6E). Under high anesthesia (2.5\%) 


\section{A}

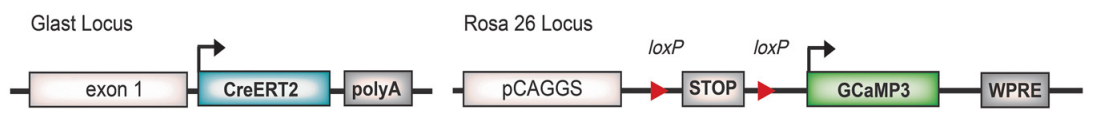

stim

B
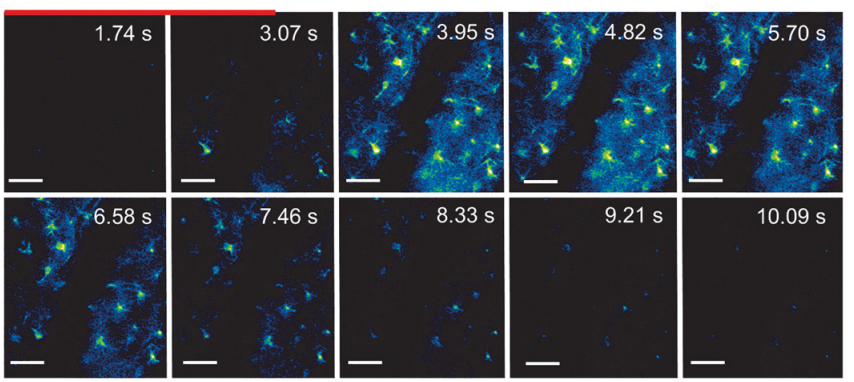

C

D

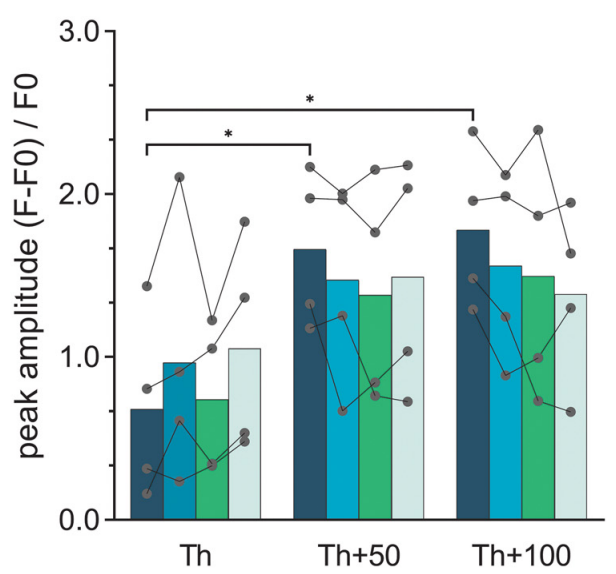

E

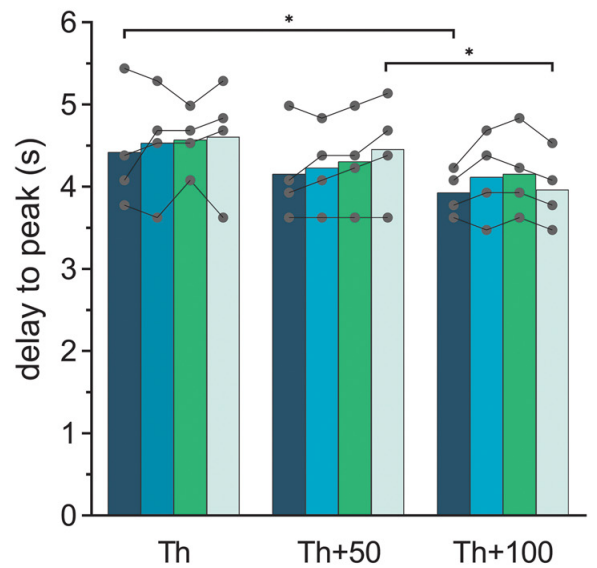

F
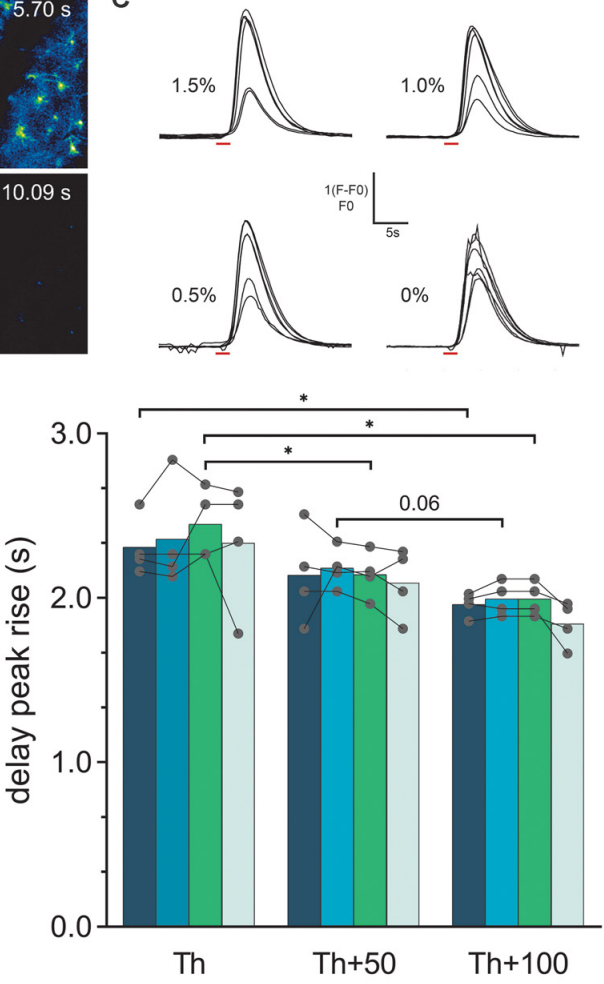

G

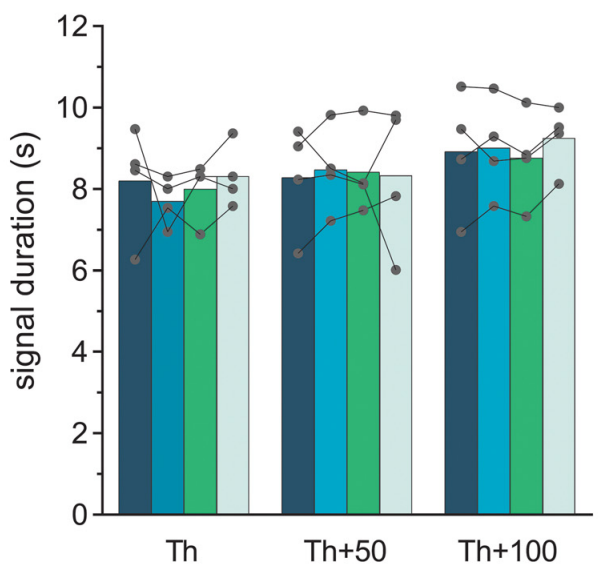

isoflurane concentration $\square 1.5 \% \square 1.0 \% \square 0.5 \% \square 0$ \%

FIGURE 4 | Astroglial $\mathrm{Ca}^{2+}$-signal elicited by electrical stimulation via the LCP surface electrodes and recorded by in vivo $2 \mathrm{P}$ imaging. (A) The experiment was performed in transgenic mice expressing the $\mathrm{Ca}^{2+}$ sensor GCaMP3 in astrocytes and cortical stimulations were applied with the 8-channel stimulation electrode. (B) $2 \mathrm{P}-\mathrm{Ca}^{2+}$ imaging sequence during electrical stimulation (red bar), scale bar $=50 \mu \mathrm{m}$. (C) Astroglial $\mathrm{Ca}^{2+}$ transients in response to electric stimulation (red bar) display a single, uniform peak at all tested isoflurane concentrations (1.5-0\%). (D) The $\mathrm{Ca}^{2+}$ peak amplitude increases with increasing stimulation intensity, especially at high isoflurane concentrations (1.5\%), while no significant effect of changing anesthesia levels at the same stimulation intensity could be detected. (E) The delay from stimulation onset to $\mathrm{Ca}^{2+}$ peak decreases with increasing stimulation intensities but is independent of isoflurane levels. (F) Rise of the Ca ${ }^{2+}$ transient to $10 \%$ of its maximum was reduced by increasing the stimulation current without changing at varying anesthesia levels of the same current intensity. (G) The astroglial Ca ${ }^{2+}$ signal duration was independent of stimulation intensity and anesthesia. Statistics: Two-Way ANOVA followed by Tukey's multiple comparisons test * $p<0.05$, $N=4$ measurements per stimulation intensity. Th, threshold. 

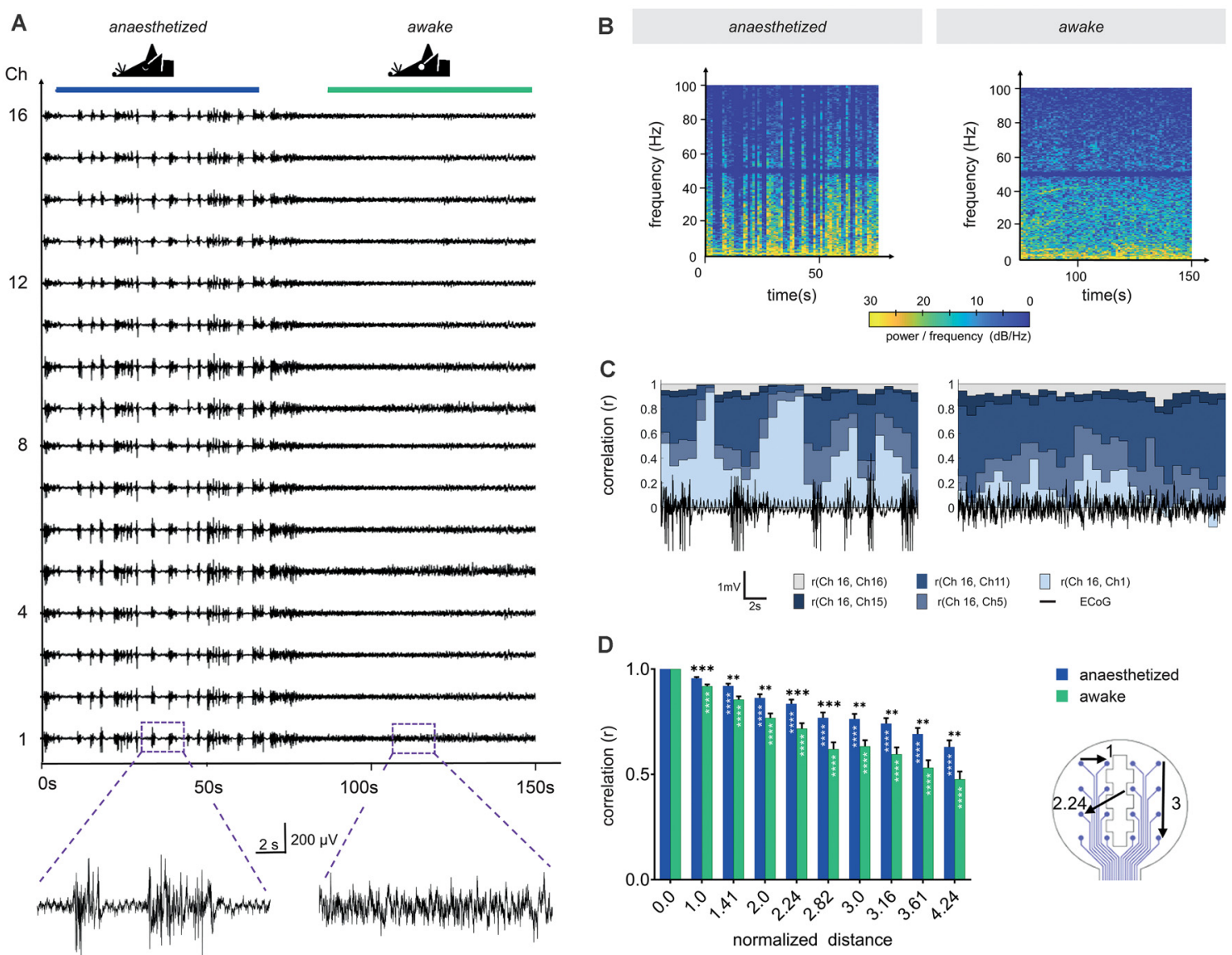

FIGURE 5 | Channel correlation analysis detects differences in brain activity between the anesthetized and the awake state. (A) Sixteen-channel ECoG recording displays the pattern change from the anesthetized state (1.5\% isoflurane) to the awake state. (B) Spectrograms in anesthetized and awake conditions represent the power spectral densities of individual frequencies over time. In the anesthetized animal, frequencies below $10 \mathrm{~Hz}$ display the highest power with intermittent synchronous activity bursts, raising the power of frequencies up to approximately $100 \mathrm{~Hz}$. Similarly, frequencies below $10 \mathrm{~Hz}$ dominated in the awake state, however, higher frequencies were continuously represented. We applied a Notch filter at $50 \mathrm{~Hz}$, represented by the dark band in this frequency range. (C) Channel similarity revealed by correlation analysis between the different electrode sites (channels) and under anesthetized and awake conditions. The similarity of the most distant recording sites [r (Ch16, Ch1)] increased substantially after synchronous burst activity under anesthesia. (D) Channel similarity (correlation) decreases with increasing distance between electrode sites (channels). In awake animals, the channel correlation is systematically lower than under anesthesia. Statistics: Two-Way ANOVA followed by Dunnett's multiple comparisons test for different distances compared to distance 0.0 of the respective anesthesia group (white stars inside bars) and Fisher's LSD for comparisons between awake and anesthetized (black stars above). Data are shown as mean $\pm \mathrm{SEM},{ }^{* *} p<0.01,{ }^{* * *} p<0.001,{ }^{* * * *} p<0.0001, N$ (anesthetized) $=21$ and $N$ (awake) $=23$ measurements per distance value

$0-0.2$ events $\left(\mathrm{Ca}^{2+}\right.$ counts) per second were detected, increasing up to 3.9 events (all classified signal types) per second in the awake mouse. This was paralleled by the normalized FI, which increased and decreased according to the inversely varying isoflurane concentration. The image correlation demonstrated fast $\mathrm{Ca}^{2+}$ signal changes (fast changing correlation result) during the awake state. Due to the image noise (which is different from image to image) the correlation coefficient is never exactly equal to 1 . The average signal of the eight ECoG channels was calculated (Figure 6F). This signal allows for an exact determination of the actual depth of anesthesia during the 2P-imaging experiment or similar experimental procedures. Overall, the animal recovers rapidly from the anesthetized state but it lasts longer returning to the anesthetized condition after an awake episode.

\section{DISCUSSION}

Three different LCP surface micro-electrodes for electrical stimulation and ECoG recordings were developed and electrochemically optimized with platinum coating. Several application examples in anesthetized and awake mice demonstrated the versatility, convenience, and reliability of the novel LCP micro-electrodes to investigate brain function in vivo. Quality assurance (impedance measurements, microscopic control) was performed to sort out electrodes with production defects. In the animal studies, surface electrodes were easy to handle and showed excellent robustness. The investigations were not disrupted by electrode damages of any kind. The possibility of combined electrical stimulation or ECoG recording with 2P-imaging in vivo opens various opportunities to study neural 


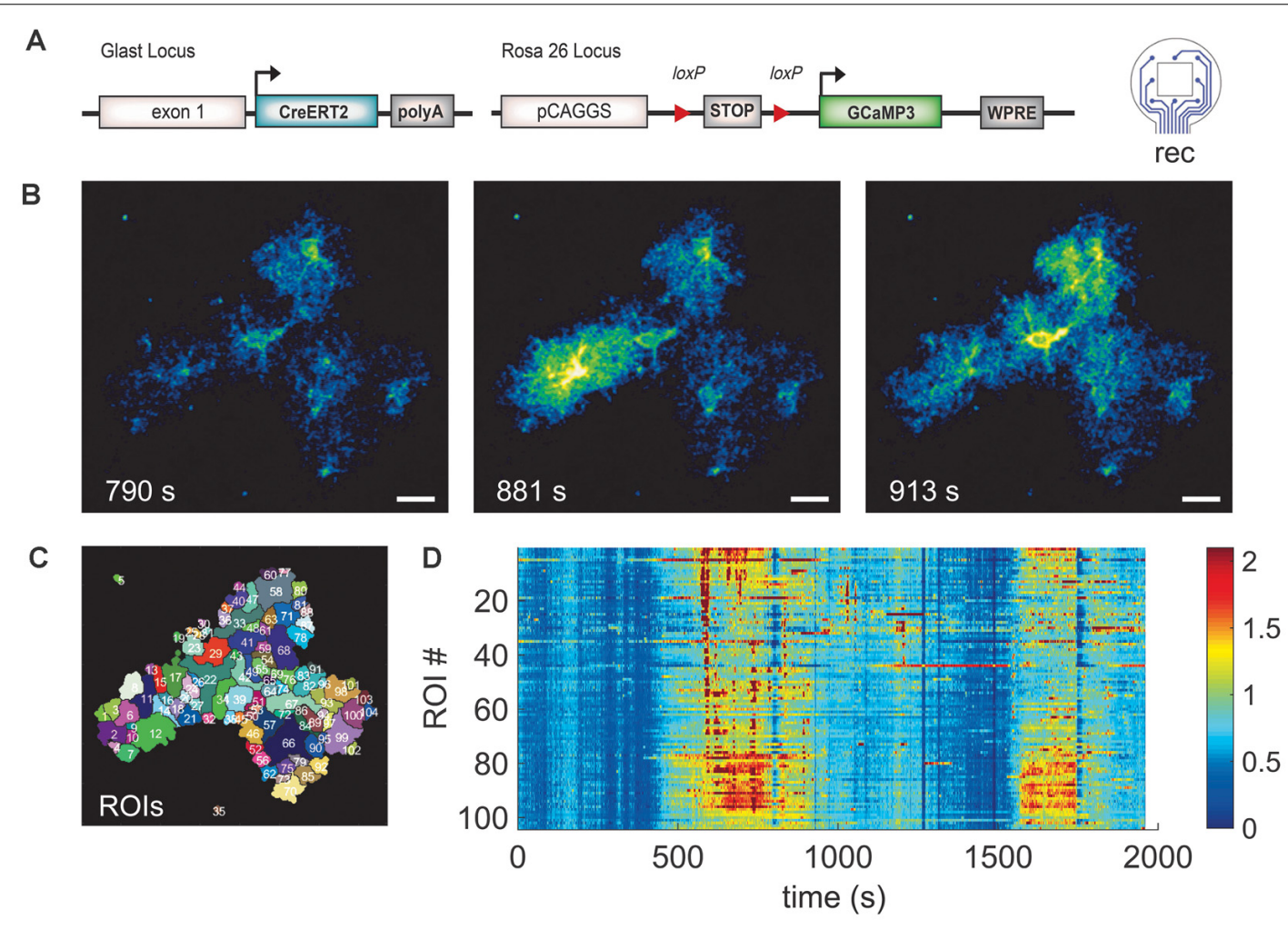

E

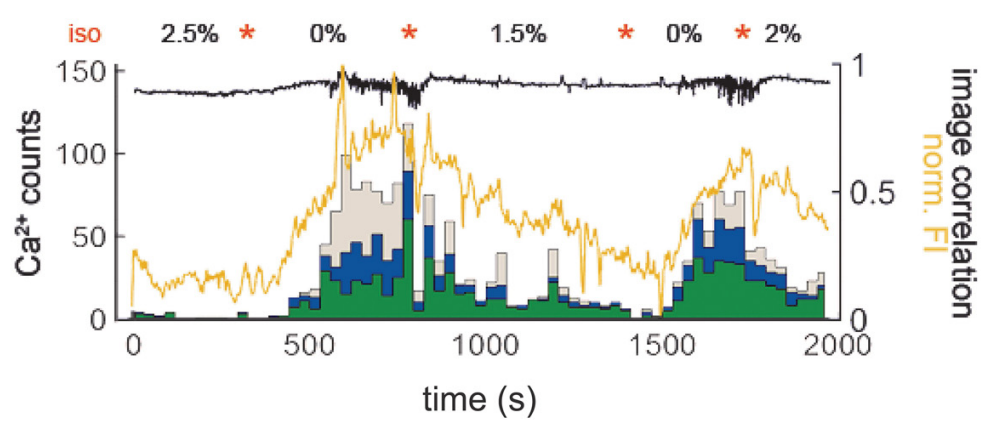

$\mathbf{F}$
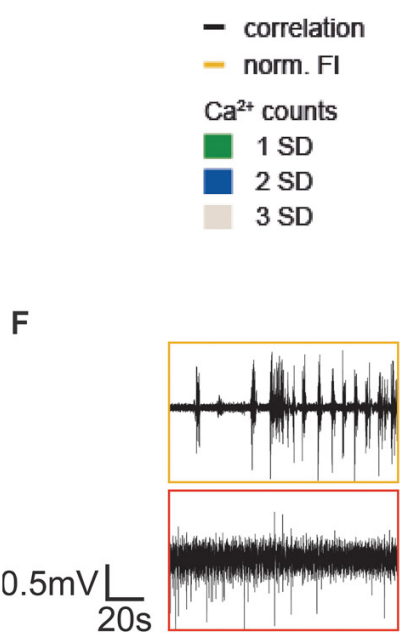

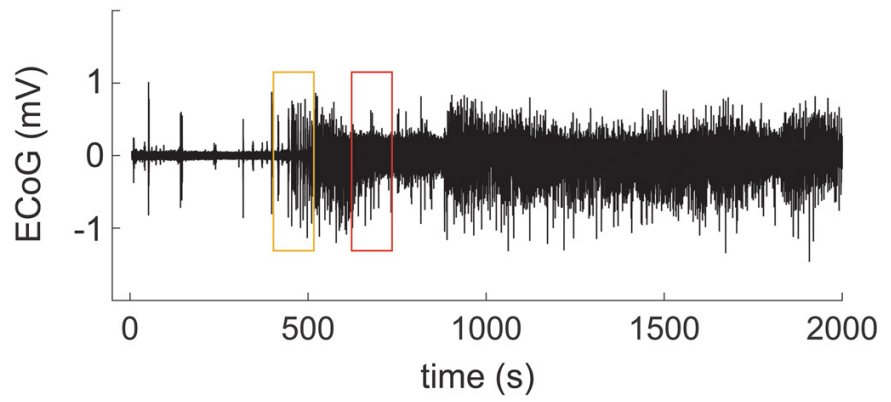

FIGURE 6 | Application of LCP electrode for ECoG recording combined with $2 \mathrm{P}-\mathrm{Ca}^{2+}$ imaging substantiates reduction of spontaneous astroglial $\mathrm{Ca}^{2+}$ signals under anesthesia. (A) Eight-channel ECoG recording and simultaneous 2P-Ca ${ }^{2+}$ imaging in transgenic mice with GCaMP3 expression in astrocytes. (B) 2P-LSM sequence displaying good cranial window quality with implanted LCP electrode 35 days post-surgery, scale bar $=20 \mu \mathrm{m}$. (C) Regions of interest (ROI) map computed by activity-dependent analysis using custom-made Matlab routines. (D) Heatmap illustrating normalized $\mathrm{Ca}^{2+}$ signal amplitudes $[(F-F 0) / F 0]$ per ROI over time. Graphs (D-F) have the same time scale and isoflurane variations (orange stars). In contrast to the anesthetized state, awake mice display higher $\mathrm{Ca}^{2+}$ signal amplitudes. (E) $\mathrm{Ca}^{2+}$ events (counts) were grouped into small (1 SD), medium (2 SD), and large (3 SD) signals and merged with corresponding normalized fluorescence intensity of the image ( $\mathrm{Fl}$, yellow trace) and image correlation (black trace). Anesthesia reduced particularly the frequency of medium and large $\mathrm{Ca}^{2+}$ signals which were highly abundant in awake animals. Increases of $\mathrm{Ca}^{2+}$ events were accompanied by rises in fluorescence amplitude and variation of image correlation. Orange stars indicate transitions between isoflurane concentrations. (F) ECoG trace displayed as average over all channels shows clear transitions in brain activity depending on the anesthesia level. 
function, e.g., to investigate neuron-glia interactions in the CNS.

\section{LCP Surface Electrodes Are Highly Biocompatible for Long-Term In vivo Observations}

Biocompatibility of neural implants is a major concern in clinical application as well as research (Polikov et al., 2005). In contrast to the reported tissue response in rodents to intracortical electrodes (Minnikanti et al., 2010; Potter et al., 2012; Salatino et al., 2017), little information was obtained about the tissue response to epidural electrodes (Schendel et al., 2013; Shokoueinejad et al., 2019). Consequently, in this work, the macroscopic and cellular biocompatibility was tested under acute (3 days post-implantation) as well as chronic conditions (28 days post-implantation). Since the LCP electrodes were used in combination with cranial windows for $2 \mathrm{P}$ imaging, we assessed the inflammatory response of glial cells by comparing animals with cranial window and electrode implant to simple cranial window surgery (sham). Neither astrocytes nor microglia displayed significant acute or chronic activation in LCP electrode carrying animals. In fact, sham animals showed an increased astroglial reactivity reflected by increased GFAP immunoreactivity, especially in the chronic application. Thus, the LCP surface electrode appears to display an even beneficial effect after cranial window surgery, likely due to the thickness of the electrodes (approx. $75 \mu \mathrm{m}$ ) filling the gap between the cortex and the glass coverslip. Thereby, the tissue may be stabilized and hemorrhages, as well as edema, may be reduced. In addition, no impact on the expression of the genetically encoded $\mathrm{Ca}^{2+}$ sensor GCaMP3 was detected, providing optimal conditions for $2 \mathrm{P}-\mathrm{Ca}^{2+}$ imaging. An additional advantage of the LCP surface electrodes is the convenient use of their inner edges as a reference system for repetitive imaging of the same ROIs in chronic imaging experiments.

\section{Cortical Stimulation Activated Local and Global Network Activity}

For in vivo stimulation of cortical tissue, the electrode arrays with the rectangular-shaped electrode sites were implanted in mice with GCaMP3 expression by principal neurons of the neocortex. The stimulation-evoked $\mathrm{Ca}^{2+}$ signals were dependent on stimulation amplitude and anesthesia level. With lower anesthesia, biphasic $\mathrm{Ca}^{2+}$ transients were observed, representing the consecutive activation of neuropil and somata. The direct effect of electrical stimulation mainly targets neuronal structures in cortical layer I with depolarizations further propagating to the somata in layer II/III. Simultaneously, the $\mathrm{Ca}^{2+}$ signal spreads intracellularly. The fluorescence intensity of the neuropil region (peak 1) did not show a significant relation to stimulation strength and anesthesia. The amplitude of the second peak involving the somata was mainly dependent on the stimulation intensity, and less on the anesthesia level. A stronger stimulation would elicit a stronger depolarization, leading to increased intracellular $\mathrm{Ca}^{2+}$ mobilization. A volatile anesthetic such as isoflurane acts on multiple targets. It reduces $\mathrm{Na}^{+}$currents while inducing $\mathrm{K}^{+}$currents, lowers resting membrane potential, depresses NMDA receptor-dependent excitatory transmission, and increases $\mathrm{GABA}_{\mathrm{A}}$ receptormediated inhibitory transmission (Franks and Lieb, 1988; Rudolph and Antkowiak, 2004; Westphalen and Hemmings, 2006; Lissek et al., 2016; Zhao et al., 2019). Thus, neuronal excitability is considerably reduced, leading to the decreased opening probability of voltage-gated $\mathrm{Ca}^{2+}$ channels for example (Study, 1994; Koyanagi et al., 2019; Timic Stamenic et al., 2019). Hence, higher peak amplitudes are observed at lower isoflurane levels. The signal drop between activation of neuropil and soma was probably a local effect of activated $\mathrm{Ca}^{2+}$ pumps restoring the intracellular $\mathrm{Ca}^{2+}$ homeostasis, counteracting the active stimulation. In a recent study (Michelson et al., 2019), a Ca ${ }^{2+}$ signal decrease in neuronal soma and neuropil is described, supporting the finding of this study.

A signal undershoot after evoked $\mathrm{Ca}^{2+}$ transients has been previously reported (Majewska et al., 2000; Collins and Thomas, 2001). This phenomenon could reflect a state of depression after strong stimulation and depletion of intracellular $\mathrm{Ca}^{2+}$ stores. Reports of volatile anesthetics' effect on ER and plasma membrane $\mathrm{Ca}^{2+}$ transport are controversial and less described in neurons than in myocytes for example (Blanck and Thompson, 1982; Collins and Thomas, 2001; Hannon and Cody, 2002). However, it is possible that the prolonged undershoot in anesthetized animals is caused by hyperactivity of the sarcoplasmic reticulum $\mathrm{Ca}^{2+}$ ATPase to refill the ER stores and delayed compensation by replenishing mechanisms. No significant changes were seen in the delay to the $\mathrm{Ca}^{2+}$ peaks nor the duration of the signal, suggesting a stereotypical neuronal $\mathrm{Ca}^{2+}$ response to stimulations (above the defined threshold). One could have expected an impact of anesthesia on the signal duration, given the fact that crucial $\mathrm{Ca}^{2+}$ extrusion mechanisms $\left[\mathrm{Na}^{+} / \mathrm{Ca}^{2+}\right.$ exchanger (NCX) and the plasma membrane $\mathrm{Ca}^{2+}$ ATPase (PMCA)] are potentially inhibited by volatile anesthesia. Corresponding studies however were mainly performed in vitro or ex vivo (Franks et al., 1995; Ay et al., 2005).

\section{Astroglial $\mathrm{Ca}^{2+}$ Events Follow Neuronal Activation After Cortical Stimulation}

To study astroglial $\mathrm{Ca}^{2+}$ responses after electrical stimulation, mice with astrocyte-specific GCaMP3 expression were used. The stimulation amplitude and anesthesia levels were varied. The rise of the $\mathrm{Ca}^{2+}$ transients started approximately $1.6 \mathrm{~s}$ to $2.6 \mathrm{~s}$ after stimulation onset and the maximum peak value was found between $3.5 \mathrm{~s}$ and $5.5 \mathrm{~s}$, when the electrical stimulation was already terminated. Together with the delay time to the $\mathrm{Ca}^{2+}$ transient peaks of neurons (approximately $0.6 \mathrm{~s}$ to $1.2 \mathrm{~s}$ for neuropil and $2 \mathrm{~s}$ to $2.5 \mathrm{~s}$ for soma), the astroglial activation followed the neuronal activation, likely due to glial responses to the release of neurotransmitters (Araque, 2008; Volterra et al., 2014; Shigetomi et al., 2016; Guerra-Gomes et al., 2017). In addition, no dependency of the $\mathrm{Ca}^{2+}$ signal peak time to the anesthesia was found which was in line with the neuronal peak time. Similarly, astroglial $\mathrm{Ca}^{2+}$ peak amplitudes increased with augmenting stimulation intensity, as seen in neurons. However, this effect was less pronounced in astrocytes. Taken together with the observation of reduced delays to 
peak amplitude with increasing stimulation strength exclusively in astrocytes, the integrative function of astrocytes following neuronal activation is highlighted (Araque et al., 2014; Caudal et al., 2020). In accordance with neuronal $\mathrm{Ca}^{2+}$ signal duration, astroglial signal duration was not significantly modulated by stimulation intensity or isoflurane levels. In contrast to neurons, astrocytes displayed longer $\mathrm{Ca}^{2+}$ events with higher variability $(3.6 \pm 0.1 \mathrm{~s}$ vs. $8.4 \pm 0.5 \mathrm{~s}$; mean $\pm \mathrm{SD})$. Previous studies revealed prominent depression of astroglial $\mathrm{Ca}^{2+}$ signaling under anesthesia (Nimmerjahn et al., 2009; Thrane et al., 2012). In contrast to our experimental setup, these studies focused on spontaneous or physiologically evoked astroglial $\mathrm{Ca}^{2+}$ activity, thus accounting for the discrepancies.

\section{Multichannel Surface Electrodes Enabled the Recording of Electrical Signals in the Cortex}

Determining the brain activity state of mice during complex in vivo experimental procedures can be crucial for successful and comprehensive data acquisition, e.g., by quantifying the depth of anesthesia (Land et al., 2012). With the LCP surface electrode arrays (round-shaped electrode sites), acquisition of low noise ECoG recordings was achieved via standard bandpass $(0.5 \mathrm{~Hz}$ to $250 \mathrm{~Hz})$ and notch filtering $(50 \mathrm{~Hz})$. No further signal filtering like wavelet denoising was required (Schweigmann et al., 2018). A channel similarity study was performed for the LCP electrodes by calculating the correlation of the individual channels. The result indicated that there was a high similarity between adjacent channels in the awake as well as in the anesthetized mouse. However, for more distant electrode sites, some signal differences were detected by decreasing channel correlation. Moreover, the channel correlation was systematically reduced in awake compared to anesthetized mice, reflecting the asynchronous network activity in awake states. In a recent study, channel correlations performed in mice and humans could resolve local activity patterns even when ECoG recording sites were less than $1 \mathrm{~mm}$ apart (Rogers et al., 2019).

Our results offer a valuable starting point for experimental designs involving evoked potentials, where ECoG activity and its propagation could be linked to functional 2P-LSM, thereby offering new options to study microcircuits across different cell populations (Mohajerani et al., 2013).

\section{Combination of In vivo 2P-LSM and ECoG Recordings to Unravel Neuron-Glia Interactions}

The successful combination of in vivo 2P-LSM and ECoG recording was demonstrated in experiments with astroglial GCaMP3 expression. After 35 days post electrode implantation, the optical window visibility was of good quality, and low noise ECoGs could be acquired, enabling the identification of anesthesia depth. Analysis of $\mathrm{Ca}^{2+}$ transients showed a variation in the number of $\mathrm{Ca}^{2+}$ events per time when the anesthetics' concentration was altered. Approximately 0.05-0.7 $\mathrm{Ca}^{2+}$ events/s in the anesthetized (isoflurane $1.5 \%$ ) and 2.5-3.9 $\mathrm{Ca}^{2+}$ events/s in the awake mouse were detected.
Previously a 10 -fold reduction of spontaneous somatic signals was described for astrocytes when the mouse was anesthetized (Thrane et al., 2012). Considering the different field of views and physiological variations, we found comparable results. Thereby, the ECoG recordings will help to understand the temporalspatial pattern of $\mathrm{Ca}^{2+}$-signals in future studies, which will link small ECoG changes with astroglial activity. Such experiments will be highly valuable to study neuron-glia interactions in vivo.

\section{Boundaries for Cortical Surface Electrode Application in Combination With 2P-LSM}

Different technologies for the development of surface electrodes exist comprising various base materials like polyimide (Choi et al., 2010; Kuzum et al., 2014; Khodagholy et al., 2015; Vomero et al., 2020), parylene (Khodagholy et al., 2013; Park et al., 2014; Richner et al., 2014; Donahue et al., 2018) or less frequently LCP (Lee et al., 2009; Min et al., 2014). The use of LCP electrodes limited the visual access for 2P-LSM due to the non-transparent, white material, therefore one or several optical windows had to be integrated to enable successful access to the cortex. Another limitation of the selected technology was in the miniaturization of the electrode sites compared to other electrode technologies, where small electrode sites in the $20 \mu \mathrm{m}$ range could be achieved (Kuzum et al., 2014; Khodagholy et al., 2015; Donahue et al., 2018). Further miniaturization might enhance the acquisition of asynchronous network activity. However, the industrial series production of the electrodes enabled a cost-effective solution which could become more and more important in decoding cell behavior and interaction in vivo.

Previously, thin, flexible, and transparent surface electrodes based on parylene $\mathrm{C}$ (with 16 channels and graphene-coated electrode sides and interconnections) were introduced for recording and stimulation application (Park et al., 2014, 2018). Fluorescent imaging had been performed at the cortical surface with one-photon excitation (UV light) over a cortex area of $4.6 \times 3.4 \mathrm{~mm}^{2}$, so that the entire electrode was visible. With a transparency of more than $90 \%$ (Park et al., 2014), $\mathrm{Ca}^{2+}$ signals could be recorded directly at the electrode sites (Park et al., 2018). Also, a comparison of parylene $C$ electrodes and platinum electrode sites was presented. The metal structure blocked the visual access, but the electrode impedance $[|\mathrm{Z}(f=10 \mathrm{~Hz})| \approx$ $1 \mathrm{M} \Omega, 200 \mu \mathrm{m}$ in diameter] was at least one-order smaller than the impedance of the graphene electrodes $[|\mathrm{Z}(f=10 \mathrm{~Hz})|$ $\approx 10 \mathrm{M} \Omega, 200 \mu \mathrm{m}$ in diameter; Park et al., 2018]. Here, our circular platinum electrode sites showed an impedance range of $|\mathrm{Z}(f=10 \mathrm{~Hz})|=29-48 \mathrm{k} \Omega$ for an electrode diameter of $150 \mu \mathrm{m}$. The $\mathrm{CSC}_{\mathrm{C}}$ of the graphene electrodes was estimated to be approximately $88 \mu \mathrm{C} / \mathrm{cm}^{2}$ (Park et al., 2018), whereas we achieved a $\mathrm{CSC}_{\mathrm{C}}$ of $10,500 \mu \mathrm{C} / \mathrm{cm}^{2}$ to $15,800 \mu \mathrm{C} / \mathrm{cm}^{2}$, indicating a higher current drive capability. A surface electrode made from PET, photoresist SU-8, gold electrode tracks, and graphene electrode sites was developed to use the transparent electrode for combined recording and deep tissue 2P-LSM (Thunemann et al., 2018). The impedance traces showed an impedance magnitude of $|\mathrm{Z}(f=10 \mathrm{~Hz})| \approx 10 \mathrm{M} \Omega-200 \mathrm{M} \Omega$ for the size of the squared 
electrode sites of $100 \mu \mathrm{m} \times 100 \mu \mathrm{m}$ (Thunemann et al., 2018). Again, the current drive capability of the graphene electrode site might be strongly limited.

Electrical recording and one photon or two-photon excitation in hippocampal tissue slices were combined using a polyimide electrode with graphene electrode sites (square-shaped 25 $\mu \mathrm{m} \times 25 \mu \mathrm{m}$; Kuzum et al., 2014). The transparency of the electrode was characterized for light wavelength in the range of $400 \mathrm{~nm}$ to $900 \mathrm{~nm}$ and showed a limitation by the polyimide (thickness $12.5 \mu \mathrm{m}$ and $25 \mu \mathrm{m}$ ) rather than graphene. For wavelengths above $600 \mathrm{~nm}$, the transparency was $80 \%$ to $85 \%$ whereas between $600 \mathrm{~nm}$ and $450 \mathrm{~nm}$ it decreases down to $10 \%$ (Kuzum et al., 2014). This might be a major concern for deep tissue 2P-LSM where e.g., only weak signals (due to tissue scattering effects) can be acquired. Another recent study (Donahue et al., 2018) pointed out the result of the combination of an electrode array made from parylene $\mathrm{C}$ and gold interconnections with two-photon imaging. The square electrode sites had a size of $25 \mu \mathrm{m} \times 25 \mu \mathrm{m}$, and the width of the interconnection lines was around $20 \mu \mathrm{m}$ at the electrode head (Donahue et al., 2018). The routing of the interconnection line was selected in a way that the visual access through the inner area of the electrode head was maximized. With that design, heating and photoelectric effects were minimized (Donahue et al., 2018). However, this could cause the problem that metal structures within the optical field might be heated up by laser light adsorption. This problem could also occur with polyimide electrodes.

Currently, there does not seem to be any electrode technology that can be used without restrictions. With the high-level microsystem-produced electrodes, a high degree of miniaturization and improved flexibility would be possible. However, general transparency could be only achieved if the electrode contacts were also realized with transparent conductive materials. But these materials still seem to have deficits in electrode impedance and current transfer capability.

\section{CONCLUSION}

We developed versatile, reliable, and cost-effective LCP surface electrodes, allowing the combination of in vivo $2 \mathrm{P}$-imaging and electrophysiology in the mouse CNS. The pilot studies highlighted the biocompatibility and the new opportunities provided by the technology. Several types of LCP electrodes,

\section{REFERENCES}

Araque, A. (2008). Astrocytes process synaptic information. Neuron Glia Biol. 4, 3-10. doi: 10.1017/S1740925X09000064

Araque, A., Carmignoto, G., Haydon, P. G., Oliet, S. H., Robitaille, R., and Volterra, A. (2014). Gliotransmitters travel in time and space. Neuron 81, 728-739. doi: 10.1016/j.neuron.2014.02.007

Araque, A., Parpura, V., Sanzgiri, R. P., and Haydon, P. G. (1999). Tripartite synapses: glia, the unacknowledged partner. Trends Neurosci. 22, 208-215. doi: 10.1016/s0166-2236(98)01349-6

Arranz, A. M., and De Strooper, B. (2019). The role of astroglia in Alzheimer's disease: pathophysiology and clinical implications. Lancet Neurol. 18, 406-414. doi: $10.1016 /$ S1474-4422(18)30490-3 optimized for tissue stimulation and low noise ECoG recording, are available to study and modulate CNS function in health and disease.

\section{DATA AVAILABILITY STATEMENT}

The original contributions presented in the study are included in the article, further inquiries can be directed to the corresponding author.

\section{ETHICS STATEMENT}

The animal study was reviewed and approved by Landesamt für Gesundheit und Verbraucherschutz of Saarland state (license numbers: 71/2013, 36/2016).

\section{AUTHOR CONTRIBUTIONS}

MS developed and optimized surface electrodes, performed imaging and recording, data analysis, wrote the initial manuscript, and conceived the study. LC performed the immunohistochemical assessment of biocompatibility, electrode implantation surgeries (optimization and preparation), imaging and recording, data analysis, wrote initial manuscript, and conceived the study. GS provided custom-made Matlab routines (MSparkles). AS and KK conceived the study and revised the manuscript. FK conceived the study, provided infrastructure, grant support, and finalized the manuscript. All authors contributed to the article and approved the submitted version.

\section{FUNDING}

This project has received funding from the European Union's Horizon 2020 research and innovation programme under the Marie Sklodowska-Curie grant agreement No. 722053 (EUGliaPhD), from the Deutsche Forschungsgemeinschaft (DFG) SPP 1757, DFG SFB894, DFG FOR2289, DFG SFB1158, H2020-FETPROACT-01-2016 Neurofibers, and from the Trier University of Applied Sciences (project MIRACLE).

\section{ACKNOWLEDGMENTS}

We are grateful to Daniel Schauenburg for expert mouse maintenance and Frank Rhode for technical assistance.

Ay, B., Wallace, D., Mantilla, C. B., and Prakash, Y. S. (2005). Differential inhibition of neuronal $\mathrm{Na}^{+}-\mathrm{Ca}^{2+}$ exchange versus store-operated $\mathrm{Ca}^{2+}$ channels by volatile anesthetics in pheochromocytoma (PC12) cells. Anesthesiology 103, 93-101. doi: 10.1097/00000542-200507000 $-00016$

Basser, P. J., and Roth, B. J. (2000). New currents in electrical stimulation of excitable tissues. Annu. Rev. Biomed. Eng. 2, 377-397. doi: 10.1146/annurev. bioeng.2.1.377

Bazargani, N., and Attwell, D. (2016). Astrocyte calcium signaling: the third wave. Nat. Neurosci. 19, 182-189. doi: 10.1038/nn.4201

Beckner, M. E. (2020). A roadmap for potassium buffering/dispersion via the glial network of the CNS. Neurochem. Int. 136:104727. doi: 10.1016/j.neuint.2020. 104727 
Bernier, L. P., Bohlen, C. J., York, E. M., Choi, H. B., Kamyabi, A., DissingOlesen, L., et al. (2019). Nanoscale surveillance of the brain by microglia via cAMP-regulated filopodia. Cell Rep. 27, 2895.e4-2908.e4. doi: 10.1016/j.celrep. 2019.05.010

Beudel, M., and Brown, P. (2016). Adaptive deep brain stimulation in Parkinson's disease. Parkinsonism Relat. Disord. 22, S123-S126. doi: 10.1016/j.parkreldis. 2015.09.028

Blanck, T. J., and Thompson, M. (1982). Enflurane and isoflurane stimulate calcium transport by cardiac sarcoplasmic reticulum. Anesth. Analg. 61, 142-145. doi: 10.1213/00000539-198202000-00015

Bojarskaite, L., Bjørnstad, D. M., Pettersen, K. H., Cunen, C., Hermansen, G. H., Åbjørsbråten, K. S., et al. (2020). Astrocytic $\mathrm{Ca}^{2+}$ signaling is reduced during sleep and is involved in the regulation of slow wave sleep. Nat. Commun. 11:3240. doi: 10.1038/s41467-020-17062-2

Brini, M., Calì, T., Ottolini, D., and Carafoli, E. (2014). Neuronal calcium signaling: function and dysfunction. Cell. Mol. Life Sci. 71, 2787-2814. doi: 10.1007/s00018-013-1550-7

Burda, J. E., Bernstein, A. M., and Sofroniew, M. V. (2016). Astrocyte roles in traumatic brain injury. Exp. Neurol. 275, 305-315. doi: 10.1016/j.expneurol. 2015.03.020

Burda, J. E., and Sofroniew, M. V. (2014). Reactive gliosis and the multicellular response to CNS damage and disease. Neuron 81, 229-248. doi: 10.1016/j. neuron.2013.12.034

Caudal, L. C., Gobbo, D., Scheller, A., and Kirchhoff, F. (2020). The paradox of astroglial $\mathrm{Ca}^{2+}$ signals at the interface of excitation and inhibition. Front. Cell. Neurosci. 14:399. doi: 10.3389/fncel.2020.609947

Chen, Y., Rommelfanger, N. J., Mahdi, A. I., Wu, X., Keene, S. T., Obaid, A., et al. (2021). How is flexible electronics advancing neuroscience research? Biomaterials 268:120559. doi: 10.1016/j.biomaterials.2020.120559

Chiang, C. H., Wang, C., Barth, K., Rahimpour, S., Trumpis, M., Duraivel, S., et al. (2021). Flexible, high-resolution thin-film electrodes for human and animal neural research. J. Neural Eng. 18:045009. doi: 10.1088/1741-2552/ac02dc

Choi, J. H., Koch, K. P., Poppendieck, W., Lee, M., and Shin, H. S. (2010). High resolution electroencephalography in freely moving mice. J. Neurophysiol. 104, 1825-1834. doi: 10.1152/jn.00188.2010

Cogan, S. F. (2008). Neural stimulation and recording electrodes. Annu. Rev. Biomed. Eng. 10, 275-309. doi: 10.1146/annurev.bioeng.10.061807.160518

Collins, R. O., and Thomas, R. C. (2001). The effect of calcium pump inhibitors on the response of intracellular calcium to caffeine in snail neurones. Cell Calcium 30, 41-48. doi: 10.1054/ceca.2001.0209

Covelo, A., and Araque, A. (2018). Neuronal activity determines distinct gliotransmitter release from a single astrocyte. eLife 7:e32237. doi: 10.7554/eLife.32237

Cupido, A., Catalin, B., Steffens, H., and Kirchhoff, F. (2014). "Surgical procedures to study microglial motility in the brain and in the spinal cord by in vivo two-photon laser-scanning microcopy," in Confocal and Multiphoton LaserScanning Microscopy of Neuronal Tissue: Applications and Quantitative Image Analysis, eds L. Bakota and R. Brandt (New York: Springer) 37-50.

Deshpande, T., Li, T., Henning, L., Wu, Z., Müller, J., Seifert, G., et al. (2020). Constitutive deletion of astrocytic connexins aggravates kainate-induced epilepsy. Glia 68, 2136-2147. doi: 10.1002/glia.23832

Donahue, M. J., Kaszas, A., Turi, G. F., Rózsa, B., Slézia, A., Vanzetta, I., et al. (2018). Multimodal characterization of neural networks using highly transparent electrode arrays. eNeuro 5:ENEURO.0187-18.2018. doi: 10.1523/ENEURO.0187-18.2018

Donat, C. K., Scott, G., Gentleman, S. M., and Sastre, M. (2017). Microglial activation in traumatic brain injury. Front. Aging Neurosci. 9:208. doi: 10.3389/fnagi.2017.00208

Durkee, C. A., and Araque, A. (2019). Diversity and specificity of astrocyte-neuron communication. Neuroscience 396, 73-78. doi: 10.1016/j.neuroscience.2018. 11.010

Englert, R., Rupp, F., Kirchhoff, F., Koch, K. P., and Schweigmann, M. (2017). Technical characterization of an 8 or 16 channel recording system to acquire electrocorticograms of mice. Curr. Dir. Biomed. Eng. 3, 595-598. doi: 10.1515/cdbme-2017-0124

Evangelidis, G. D., and Psarakis, E. Z. (2008). Parametric image alignment using enhanced correlation coefficient maximization. IEEE Trans. Pattern Anal. Mach. Intell. 30, 1858-1865. doi: 10.1109/TPAMI.2008.113
Franks, J. J., Horn, J. L., Janicki, P. K., and Singh, G. (1995). Stable inhibition of brain synaptic plasma membrane calcium ATPase in rats anesthetized with halothane. Anesthesiology 82, 118-128. doi: 10.1097/00000542-19950100000016

Franks, N. P., and Lieb, W. R. (1988). Volatile general anaesthetics activate a novel neuronal $\mathrm{K}^{+}$current. Nature 333, 662-664. doi: 10.1038/333662a0

Gómez-Gonzalo, M., Martin-Fernandez, M., Martínez-Murillo, R., Mederos, S., Hernández-Vivanco, A., Jamison, S., et al. (2017). Neuron-astrocyte signaling is preserved in the aging brain. Glia 65, 569-580. doi: 10.1002/glia.23112

Guerra-Gomes, S., Sousa, N., Pinto, L., and Oliveira, J. F. (2017). Functional roles of astrocyte calcium elevations: from synapses to behavior. Front. Cell. Neurosci. 11:427. doi: 10.3389/fncel.2017.00427

Guo, Z. V., Hires, S. A., Li, N., O’Connor, D. H., Komiyama, T., Ophir, E., et al. (2014). Procedures for behavioral experiments in head-fixed mice. PLoS One 9:e88678. doi: 10.1371/journal.pone.0088678

Guo, M., Wang, J., Zhao, Y., Feng, Y., Han, S., Dong, Q., et al. (2020). Microglial exosomes facilitate $\alpha$-synuclein transmission in Parkinson's disease. Brain 143, 1476-1497. doi: 10.1093/brain/awaa090

Hannon, J. D., and Cody, M. J. (2002). Effects of volatile anesthetics on sarcolemmal calcium transport and sarcoplasmic reticulum calcium content in isolated myocytes. Anesthesiology 96, 1457-1464. doi: 10.1097/00000542200206000-00027

Harada, K., Ito, M., Wang, X., Tanaka, M., Wongso, D., Konno, A., et al. (2017). Red fluorescent protein-based cAMP indicator applicable to optogenetics and in vivo imaging. Sci. Rep. 7:7351. doi: 10.1038/s41598-017-07820-6

Heuser, K., Nome, C. G., Pettersen, K. H., Åbjørsbråten, K. S., Jensen, V., Tang, W., et al. (2018). $\mathrm{Ca}^{2+}$ signals in astrocytes facilitate spread of epileptiform activity. Cereb. Cortex 28, 4036-4048. doi: 10.1093/cercor/bhy196

International Multiple Sclerosis Genetics Consortium. (2019). Multiple sclerosis genomic map implicates peripheral immune cells and microglia in susceptibility. Science 365:eaav7188. doi: 10.1126/science.aav7188

Jahn, H. M., Kasakow, C. V., Helfer, A., Michely, J., Verkhratsky, A., Maurer, H. H., et al. (2018). Refined protocols of tamoxifen injection for inducible DNA recombination in mouse astroglia. Sci. Rep. 8:5913. doi: 10.1038/s41598-01824085-9

Karus, C., Mondragão, M. A., Ziemens, D., and Rose, C. R. (2015). Astrocytes restrict discharge duration and neuronal sodium loads during recurrent network activity. Glia 63, 936-957. doi: 10.1002/glia.22793

Khodagholy, D., Doublet, T., Quilichini, P., Gurfinkel, M., Leleux, P., Ghestem, A., et al. (2013). in vivo recordings of brain activity using organic transistors. Nat. Commun. 4:1575. doi: 10.1038/ncomms2573

Khodagholy, D., Gelinas, J. N., Thesen, T., Doyle, W., Devinsky, O., Malliaras, G. G., et al. (2015). NeuroGrid: recording action potentials from the surface of the brain. Nat. Neurosci. 18, 310-315. doi: 10.1038/nn.3905

Kirsch, D. L., and Nichols, F. (2013). Cranial electrotherapy stimulation for treatment of anxiety, depression, and insomnia. Psychiatr. Clin. North Am. 36, 169-176. doi: 10.1016/j.psc.2013.01.006

Kislin, M., Mugantseva, E., Molotkov, D., Kulesskaya, N., Khirug, S., Kirilkin, I., et al. (2014). Flat-floored air-lifted platform: a new method for combining behavior with microscopy or electrophysiology on awake freely moving rodents. J. Vis. Exp. 88:e51869. doi: 10.3791/51869

Koyanagi, Y., Torturo, C. L., Cook, D. C., Zhou, Z., and Hemmings, H. C. (2019). Role of specific presynaptic calcium channel subtypes in isoflurane inhibition of synaptic vesicle exocytosis in rat hippocampal neurones. Br. J. Anaesth. 123, 219-227. doi: 10.1016/j.bja.2019.03.029

Kuzum, D., Takano, H., Shim, E., Reed, J. C., Juul, H., Richardson, A. G. et al. (2014). Transparent and flexible low noise graphene electrodes for simultaneous electrophysiology and neuroimaging. Nat. Commun. 5:5259. doi: $10.1038 /$ ncomms6259

Land, R., Engler, G., Kral, A., and Engel, A. K. (2012). Auditory evoked bursts in mouse visual cortex during isoflurane anesthesia. PLoS One 7:e49855. doi: 10.1371/journal.pone.0049855

Lee, S. W., Seo, J. M., Ha, S., Kim, E. T., Chung, H., and Kim, S. J. (2009). Development of microelectrode arrays for artificial retinal implants using liquid crystal polymers. Invest. Ophthalmol. Vis. Sci. 50, 5859-5866. doi: 10.1167/iovs.09-3743

Lissek, T., Obenhaus, H. A., Ditzel, D. A., Nagai, T., Miyawaki, A., Sprengel, R., et al. (2016). General anesthetic conditions induce network synchrony 
and disrupt sensory processing in the cortex. Front. Cell. Neurosci. 10:64. doi: $10.3389 /$ fncel.2016.00064

Majewska, A., Brown, E., Ross, J., and Yuste, R. (2000). Mechanisms of calcium decay kinetics in hippocampal spines: role of spine calcium pumps and calcium diffusion through the spine neck in biochemical compartmentalization. J. Neurosci. 20, 1722-1734. doi: 10.1523/JNEUROSCI.20-05-01 722.2000

Michelson, N. J., Eles, J. R., Vazquez, A. L., Ludwig, K. A., and Kozai, T. D. Y. (2019). Calcium activation of cortical neurons by continuous electrical stimulation: frequency dependence, temporal fidelity, and activation density. J. Neurosci. Res. 97, 620-638. doi: 10.1002/jnr.24370

Min, K. S., Lee, C. J., Jun, S. B., Kim, J., Lee, S. E., Shin, J., et al. (2014). A liquid crystal polymer-based neuromodulation system: an application on animal model of neuropathic pain. Neuromodulation 17, 160-169. doi: 10.1111/ner. 12093

Minnikanti, S., Pereira, M. G., Jaraiedi, S., Jackson, K., Costa-Neto, C. M., Li, Q., et al. (2010). in vivo electrochemical characterization and inflammatory response of multiwalled carbon nanotube-based electrodes in rat hippocampus. J. Neural Eng. 7:16002. doi: 10.1088/1741-2560/7/1/016002

Mohajerani, M. H., Chan, A. W., Mohsenvand, M., LeDue, J., Liu, R., McVea, D. A., et al. (2013). Spontaneous cortical activity alternates between motifs defined by regional axonal projections. Nat. Neurosci. 16, 1426-1435. doi: $10.1038 / \mathrm{nn} .3499$

Mori, T., Tanaka, K., Buffo, A., Wurst, W., Kühn, R., and Götz, M. (2006). Inducible gene deletion in astroglia and radial glia-a valuable tool for functional and lineage analysis. Glia 54, 21-34. doi: 10.1002/glia.20350

Nikolic, L., Shen, W., Nobili, P., Virenque, A., Ulmann, L., and Audinat, E. (2018). Blocking TNF $\alpha$-driven astrocyte purinergic signaling restores normal synaptic activity during epileptogenesis. Glia 66, 2673-2683. doi: 10.1002/glia.23519

Nimmerjahn, A., Kirchhoff, F., and Helmchen, F. (2005). Resting microglial cells are highly dynamic surveillants of brain parenchyma in vivo. Science 308, 1314-1318. doi: 10.1126/science.1110647

Nimmerjahn, A., Mukamel, E. A., and Schnitzer, M. J. (2009). Motor behavior activates Bergmann glial networks. Neuron 62, 400-412. doi: 10.1016/j.neuron. 2009.03.019

Obien, M. E., Deligkaris, K., Bullmann, T., Bakkum, D. J., and Frey, U. (2014). Revealing neuronal function through microelectrode array recordings. Front. Neurosci. 8:423. doi: 10.3389/fnins.2014.00423

Park, D.-W., Ness, J. P., Brodnick, S. K., Esquibel, C., Novello, J., Atry, F., et al. (2018). Electrical neural stimulation and simultaneous in vivo monitoring with transparent graphene electrode arrays implanted in GCaMP6f mice. ACS Nano 12, 148-157. doi: 10.1021/acsnano.7b04321

Park, D.-W., Schendel, A. A., Mikael, S., Brodnick, S. K., Richner, T. J., Ness, J. P., et al. (2014). Graphene-based carbon-layered electrode array technology for neural imaging and optogenetic applications. Nat. Commun. 5:5258. doi: $10.1038 /$ ncomms6258

Parpura, V., Basarsky, T. A., Liu, F., Jeftinija, K., Jeftinija, S., and Haydon, P. G. (1994). Glutamate-mediated astrocyte neuron signaling. Nature 369, 744-747. doi: 10.1038/369744a0

Paukert, M., Agarwal, A., Cha, J., Doze, V. A., Kang, J. U., and Bergles, D. E. (2014). Norepinephrine controls astroglial responsiveness to local circuit activity. Neuron 82, 1263-1270. doi: 10.1016/j.neuron.2014.04.038

Polikov, V. S., Tresco, P. A., and Reichert, W. M. (2005). Response of brain tissue to chronically implanted neural electrodes. J. Neurosci. Methods 148, 1-18. doi: 10.1016/j.jneumeth.2005.08.015

Pologruto, T. A., Sabatini, B. L., and Svoboda, K. (2003). ScanImage: flexible software for operating laser scanning microscopes. Biomed. Eng. Online 2:13. doi: 10.1186/1475-925X-2-13

Potter, K. A., Buck, A. C., Self, W. K., and Capadona, J. R. (2012). Stab injury and device implantation within the brain results in inversely multiphasic neuroinflammatory and neurodegenerative responses. J. Neural Eng. 9:046020. doi: 10.1088/1741-2560/9/4/046020

Prinz, M., Jung, S., and Priller, J. (2019). Microglia biology: one century of evolving concepts. Cell 179, 292-311. doi: 10.1016/j.cell.2019.08.053

Radman, T., Ramos, R. L., Brumberg, J. C., and Bikson, M. (2009). Role of cortical cell type and morphology in subthreshold and suprathreshold uniform electric field stimulation in vitro. Brain Stimul. 2, 215.e3-228.e3. doi: 10.1016/j.brs. 2009.03.007
Rattay, F. (1998). Analysis of the electrical excitation of CNS neurons. IEEE Trans. Biomed. Eng. 45, 766-772. doi: 10.1109/10.678611

Richner, T. J., Thongpang, S., Brodnick, S. K., Schendel, A. A., Falk, R. W., Krugner-Higby, L. A., et al. (2014). Optogenetic micro-electrocorticography for modulating and localizing cerebral cortex activity. J. Neural Eng. 11:016010. doi: 10.1088/1741-2560/11/1/016010

Rogers, N., Hermiz, J., Ganji, M., Kaestner, E., Kılıç, K., Hossain, L., et al. (2019). Correlation structure in micro-ECoG recordings is described by spatially coherent components. PLoS Comput. Biol. 15:e1006769. doi: 10.1371/journal. pcbi.1006769

Ross, W., Fleidervish, I., and Lasser-Ross, N. (2013). Imaging sodium in axons and dendrites. Cold Spring Harb. Protoc. 2013, 433-437. doi: 10.1101/pdb. prot074310

Rudolph, U., and Antkowiak, B. (2004). Molecular and neuronal substrates for general anaesthetics. Nat. Rev. Neurosci. 5, 709-720. doi: 10.1038/nrn1496

Rusakov, D. A. (2015). Disentangling calcium-driven astrocyte physiology. Nat. Rev. Neurosci. 16, 226-233. doi: 10.1038/nrn3878

Salatino, J. W., Ludwig, K. A., Kozai, T. D. Y., and Purcell, E. K. (2017). Glial responses to implanted electrodes in the brain. Nat. Biomed. Eng. 1, 862-877. doi: 10.1038/s41551-017-0154-1

Schendel, A. A., Thongpang, S., Brodnick, S. K., Richner, T. J., Lindevig, B. D., Krugner-Higby, L., et al. (2013). A cranial window imaging method for monitoring vascular growth around chronically implanted micro-ECoG devices. J. Neurosci. Methods 218, 121-130. doi: 10.1016/j.jneumeth.2013. 06.001

Schweigmann, M., Koch, K. P., Auler, F., and Kirchhoff, F. (2018). Improving electrocorticograms of awake and anaesthetized mice using wavelet denoising. Curr. Dir. Biomed. Eng. 4, 469-472. doi: 10.1515/cdbme-2018-0112

Shigetomi, E., Patel, S., and Khakh, B. S. (2016). Probing the complexities of astrocyte calcium signaling. Trends Cell Biol. 26, 300-312. doi: 10.1016/j.tcb. 2016.01.003

Shokoueinejad, M., Park, D. W., Jung, Y. H., Brodnick, S. K., Novello, J., Dingle, A., et al. (2019). Progress in the field of micro-electrocorticography. Micromachines 10:62. doi: 10.3390/mi10010062

Simons, M., and Nave, K.-A. (2015). Oligodendrocytes: myelination and axonal support. Cold Spring Harb. Perspect. Biol. 8:a020479. doi: 10.1101/cshperspect. a020479

Sohal, H. S., Clowry, G. J., Jackson, A., O’Neill, A., and Baker, S. N. (2016), Mechanical flexibility reduces the foreign body response to long-term implanted microelectrodes in rabbit cortex. PLoS One 11:e0165606. doi: 10.1371/journal.pone.0165606

Study, R. E. (1994). Isoflurane inhibits multiple voltage-gated calcium currents in hippocampal pyramidal neurons. Anesthesiology 81, 104-116. doi: 10.1097/00000542-199407000-00016

Swire, M., and Ffrench-Constant, C. (2018). Seeing is believing: myelin dynamics in the adult CNS. Neuron 98, 684-686. doi: 10.1016/j.neuron.2018.05.005

Thrane, A. S., Thrane, V. R., Zeppenfeld, D., Lou, N., Xu, Q., Nagelhus, E. A., et al. (2012). General anesthesia selectively disrupts astrocyte calcium signaling in the awake mouse cortex. Proc. Natl. Acad. Sci. U S A 109, 18974-18979. doi: 10.1073/pnas. 1209448109

Thunemann, M., Lu, Y., Liu, X., Kılıç, K., Desjardins, M., Vandenberghe, M., et al. (2018). Deep 2-photon imaging and artifact-free optogenetics through transparent graphene microelectrode arrays. Nat. Commun. 9:2035. doi: 10.1038/s41467-018-04457-5

Timic Stamenic, T., Feseha, S., Valdez, R., Zhao, W., Klawitter, J., and Todorovic, S. M. (2019). Alterations in oscillatory behavior of central medial thalamic neurons demonstrate a key role of CaV3.1 isoform of T-channels during isoflurane-induced anesthesia. Cereb. Cortex 29, 4679-4696. doi: $10.1093 /$ cercor/bhz002

Traiffort, E., Kassoussi, A., Zahaf, A., and Laouarem, Y. (2020). Astrocytes and microglia as major players of myelin production in normal and pathological conditions. Front. Cell. Neurosci. 14:79. doi: 10.3389/fncel.2020.00079

Verkhratsky, A., and Nedergaard, M. (2018). Physiology of astroglia. Physiol. Rev. 98, 239-389. doi: 10.1152/physrev.00042.2016

Volterra, A., Liaudet, N., and Savtchouk, I. (2014). Astrocyte $\mathrm{Ca}^{2+}$ signalling: an unexpected complexity. Nat. Rev. Neurosci. 15, 327-335. doi: 10.1038/nrn3725

Vomero, M., Porto Cruz, M. F., Zucchini, E., Ciarpella, F., Delfino, E., Carli, S., et al. (2020). Conformable polyimide-based $\mu$ ECoGs: bringing the 
electrodes closer to the signal source. Biomaterials 255:120178. doi: 10.1016/j. biomaterials.2020.120178

Westphalen, R. I., and Hemmings, H. C. Jr. (2006). Volatile anesthetic effects on glutamate versus GABA release from isolated rat cortical nerve terminals: basal release. J. Pharmacol. Exp. Ther. 316, 208-215. doi: 10.1124/jpet.105.090647

Woods, V., Trumpis, M., Bent, B., Palopoli-Trojani, K., Chiang, C. H., Wang, C., et al. (2018). Long-term recording reliability of liquid crystal polymer $\Omega E C o G$ arrays. J. Neural Eng. 15:066024. doi: 10.1088/1741-2552/aae39d

Xie, Z., Yang, Q., Song, D., Quan, Z., and Qing, H. (2020). Optogenetic manipulation of astrocytes from synapses to neuronal networks: a potential therapeutic strategy for neurodegenerative diseases. Glia 68, 215-226. doi: 10.1002/glia.23693

Ye, H., and Steiger, A. (2015). Neuron matters: electric activation of neuronal tissue is dependent on the interaction between the neuron and the electric field. J. Neuroeng. Rehabil. 12:65. doi: 10.1186/s12984-015-0061-1

Yeung, M. S. Y., Djelloul, M., Steiner, E., Bernard, S., Salehpour, M., Possnert, G., et al. (2019). Dynamics of oligodendrocyte generation in multiple sclerosis. Nature 566, 538-542. doi: 10.1038/s41586-018-0842-3

Yun, S. P., Kam, T.-I., Panicker, N., Kim, S., Oh, Y., Park, J. S., et al. (2018). Block of A1 astrocyte conversion by microglia is neuroprotective in models of Parkinson's disease. Nat. Med. 24, 931-938. doi: 10.1038/s41591-018 $-0051-5$

Zhao, W., Zhang, M., Liu, J., Liang, P., Wang, R., Hemmings, H. C., et al. (2019). Isoflurane modulates hippocampal cornu ammonis pyramidal neuron excitability by inhibition of both transient and persistent sodium currents in mice. Anesthesiology 131, 94-104. doi: 10.1097/ALN.0000000000002753

Ziemens, D., Oschmann, F., Gerkau, N. J., and Rose, C. R. (2019). Heterogeneity of activity-induced sodium transients between astrocytes of the mouse hippocampus and neocortex: mechanisms and consequences. J. Neurosci. 39, 2620-2634. doi: 10.1523/JNEUROSCI.2029-18.2019

Conflict of Interest: The authors declare that the research was conducted in the absence of any commercial or financial relationships that could be construed as a potential conflict of interest.

Publisher's Note: All claims expressed in this article are solely those of the authors and do not necessarily represent those of their affiliated organizations, or those of the publisher, the editors and the reviewers. Any product that may be evaluated in this article, or claim that may be made by its manufacturer, is not guaranteed or endorsed by the publisher.

Copyright (C) 2021 Schweigmann, Caudal, Stopper, Scheller, Koch and Kirchhoff. This is an open-access article distributed under the terms of the Creative Commons Attribution License (CC BY). The use, distribution or reproduction in other forums is permitted, provided the original author(s) and the copyright owner(s) are credited and that the original publication in this journal is cited, in accordance with accepted academic practice. No use, distribution or reproduction is permitted which does not comply with these terms. 